\title{
Antibiotic-Resistant Salmonella in the Food Supply and the Potential Role of Antibiotic Alternatives for Control
}

\author{
Divek V. T. Nair ${ }^{1}$, Kumar Venkitanarayanan ${ }^{2}$ and Anup Kollanoor Johny ${ }^{1, * \mathbb{C}}$ \\ 1 Department of Animal Science, University of Minnesota, Saint Paul, MN 55108 USA; valsa002@umn.edu \\ 2 Department of Animal Science, University of Connecticut, Storrs, CT 06269, USA; \\ kumar.venkitanarayanan@uconn.edu \\ * Correspondence: anupjohn@umn.edu; Tel.: +1-612-625-5277 (Office)
}

Received: 19 June 2018; Accepted: 3 October 2018; Published: 11 October 2018

\begin{abstract}
Salmonella enterica is one of the most ubiquitous enteropathogenic bacterial species on earth, and comprises more than 2500 serovars. Widely known for causing non-typhoidal foodborne infections (95\%), and enteric (typhoid) fever in humans, Salmonella colonizes almost all warm- and cold-blooded animals, in addition to its extra-animal environmental strongholds. The last few decades have witnessed the emergence of highly virulent and antibiotic-resistant Salmonella, causing greater morbidity and mortality in humans. The emergence of several Salmonella serotypes resistant to multiple antibiotics in food animals underscores a significant food safety hazard. In this review, we discuss the various antibiotic-resistant Salmonella serotypes in food animals and the food supply, factors that contributed to their emergence, their antibiotic resistance mechanisms, the public health implications of their spread through the food supply, and the potential antibiotic alternatives for controlling them.
\end{abstract}

Keywords: Salmonella; antibiotic resistant; food supply; serotypes; antibiotic alternatives; control

\section{Introduction}

Antibiotic resistance is a global phenomenon resulting in the emergence of pathogens with resistance to clinically important antibiotics, necessitating new treatment strategies [1]. Antibiotic-resistant bacteria cause life-threatening illness in humans and pose a significant threat to health and well-being. It is estimated that antibiotic-resistant pathogens cause $\sim 2$ million illnesses and 23,000 deaths annually in the U.S. These illnesses cause an additional healthcare cost of $\$ 20$ billion and a productivity loss of $\$ 35$ billion to the U.S. economy. Also, extensive use of antibiotics predisposes individuals to other serious illnesses, such as the Clostridium difficile infections that result in an estimated 250,000 infections and 14,000 deaths, annually [2].

Antibiotic resistance in foodborne pathogens such as Salmonella is a major concern for public health safety. More focus is required to target them in the animal foods supply [2]. Salmonella is difficult to eliminate from its reservoir hosts, and food animals often serve as reservoirs of the pathogen. Non-typhoidal Salmonella causes the highest number of illnesses, hospitalizations, and deaths associated with foodborne illness [3]. It is associated with more than 1,200,000 illnesses annually, and among these at least 100,000 infections are due to antibiotic-resistant Salmonella, including those that are resistant to clinically-important drugs such as ceftriaxone (36,000 illnesses/year) and ciprofloxacin (33,000 illnesses/year) [2]. In fact, Salmonella isolates conferring resistance to $\geq 5$ antibiotics accounted for more than 66,000 illnesses from 2009 to 2011 in the U.S. [2].

Salmonella is a Gram-negative, facultatively anaerobic bacillus belonging to the Enterobacteriaceae family. The genus Salmonella is composed of two taxonomical species, Salmonella bongori, and Salmonella 
enterica, with all medically relevant salmonellae a part of the latter. Salmonella enterica is a diverse species of bacteria consisting of more than 2500 different serovars. The pathogen can be host-adapted, host-restricted, or generalistic, depending on the broad range of hosts that it can infect. The pathogen is ubiquitously present in the human food chain, and is frequently associated with outbreaks of foodborne disease. Outbreak investigations have identified food sources such as vegetables, fresh produce, cereals, cantaloupes, alfalfa sprouts, pistachios, fruit/fruit pulp, ground beef and turkeys, chicken meat and pork, tuna, dried/shredded coconut, and tomatoes as vehicles of Salmonella-associated foodborne outbreaks in the past decade [4]. The situation has been aggravated, since antibiotic-resistant clones are frequently implied as the etiological agents in these outbreaks leading to treatment failures, higher risk of bloodstream infections, and increased rate of hospitalizations.

Recently, drug-resistant Salmonella has been associated with a considerable number of outbreaks in the U.S. A non-typhoidal Salmonella serovar, S. Urbana, caused disease outbreak through papayas in 2017, and the isolates showed resistance to streptomycin and intermediate resistance to tetracycline [5]. Another serovar, S. Poona, caused multistate disease outbreaks through cucumbers in 2015, and the isolates were resistant to either tetracycline or nalidixic acid. In addition, the nalidixic acid-resistant isolate showed a decreased susceptibility to ciprofloxacin, a clinically important drug used in children against Salmonella infection [6]. Multidrug-resistant Salmonella I 4,[5],12:i: caused foodborne illness outbreaks through contaminated pork products in 2015, which resulted in severe infection in humans. The isolated strains were resistant to multiple antibiotics, including ampicillin, streptomycin, sulfisoxazole, and tetracycline [7]. In addition, S. Enteritidis isolated from raw, frozen, and stuffed chicken entrees associated with multistate disease outbreaks were resistant to ampicillin and tetracycline [8]. In 2014, S. Heidelberg was involved in an outbreak through mechanically separated chicken, and $67 \%$ of Salmonella isolates identified were resistant to three or more classes of antibiotics [9]. In addition, in 2011, multidrug-resistant $S$. Typhimurium, S. Heidelberg, and S. Hadar were associated with disease outbreaks in the U.S. through contaminated ground beef, ground turkeys, and turkey burgers, respectively [10-12]. These reports indicate the frequent involvement of antibiotic-resistant Salmonella in the human food chain, necessitating the exploration of novel non-antibiotic interventions to counteract the pathogen in reservoirs, including food animals.

\section{Emergence and Spread of Antibiotic-Resistant Bacteria}

Antibiotics are used in food animal production to promote growth and to prevent, (prophylactic), treat (therapeutic), and control (metaphylactic) infectious diseases $[13,14]$. Previous studies indicated that the use of antibiotics for non-therapeutic purposes in poultry, swine, and cattle outweighed what has been used in humans by several-fold with respect to the amount of drugs consumed $[13,15]$. The extensive use of antibiotics in the animal production systems for the purposes mentioned above has also contributed to the development of drug-resistant bacteria. The close association of these bacteria has also been identified in the human food chain. For example, drug-resistant bacteria have been identified from various environmental samples, farms, and retail meat products [13,14,16-19]. In addition, the non-judicious use of antibiotics has been attributed to foodborne disease outbreaks where the etiological agents have been identified as resistant clones. Although a mandatory withdrawal period is necessary for avoiding the deposition of antibiotic residues in meat, milk, and eggs, lack of proper monitoring could result in residue deposition in the human food chain, resulting in the colonization of resistant bacteria in the human digestive tract [20].

A variety of microorganisms are present outside the host, including those found in water, soil, air, and other related environments. These environmental microorganisms are excellent sources of antimicrobial resistance genes ("environmental resistomes"). "Resistome" is a broad term that describes the presence of all antibiotic resistance genes found in free-living organisms in the environment or commensal microbes. The resistome plays a critical role in transferring antimicrobial resistance to pathogenic microorganisms, and directly affects human health by entering the food chain [21]. Studies have revealed that commensal bacterial species such as the lactic acid bacteria carry resistance genes 
and might serve as reservoirs of resistant genes for entero-pathogens. For example, tetracycline, vancomycin, and erythromycin resistance genes have been identified from lactic acid bacteria isolated from fermented dairy products, sausages, and raw meat products including poultry, beef, and pork [22].

The interaction between the different components in a food chain or the environment further contributes to the spread of antibiotic resistance across species [14]. Although humans contract infections from farm animals, pets, fresh produce, meat, eggs, and other agricultural and non-agricultural food products, there are multiple entry routes for pathogens to these vehicles [14]. Foodborne pathogens such as Salmonella enter a farm from different sources, such as water, litter, personnel, equipment, vehicles, rodents, insects, and pets. In addition, the movement of portable equipment and vehicles can act as a vector for carrying the pathogen to the farm environment or slaughterhouse [23]. Similarly, antibiotic-resistant bacteria also spread through truck washing systems, lairage, barn floor, barn flush, and holding pens, and potentially end up in animal carcasses during slaughter [24]. Irrespective of the antibiotic use, antibiotic-resistant pathogens such as $S$. Typhimurium have been recovered from swine and poultry housed in antibiotic-free production systems, highlighting the possible role of environmental factors and vectors such as rodents, insects, and birds in spreading resistance [14,17-19].

The fecal excretion of antibiotic-resistant pathogens such as Salmonella from livestock and poultry causes the contamination of the farm environment and water systems. Faulty municipal drainage systems could also result in the spread of resistant bacteria from humans to the waterways and the environment [25]. The use of fecal waste as manure in agricultural lands also contributes to the spread of antibiotic resistance, especially in fresh produce. Antibiotic-resistant foodborne pathogens such as Salmonella, E. coli, and Shigella have frequently been recovered from fresh produce locally grown in the U.S. or imported from other countries [26]. The application of pesticides, soil contaminated with livestock feces, and the spraying or irrigation of contaminated water cause the spread of resistant bacteria to fruits, vegetables, and fresh produce [27]. The contamination of waterways also contributes to the pool of resistant bacteria in agriculture and aquaculture. Aquaculture isolates have shown similar resistance patterns to the isolates recovered from terrestrial agriculture, indicating possible contamination of water sources from farmland [25].

The development and spread of antibiotic resistance are complicated processes involving different components of the human food chain, and could be a result of the intense use of antibiotics in food animal agriculture, in addition to other contributors. With such severe concerns of antibiotic resistance development in various pathogens, including the emerging multidrug-resistant strains, the Food and Drug Administration (FDA) has recently introduced the Veterinary Feed Directive (VFD) that necessitates the supervision of veterinarians before using clinically-important antibiotics in treating production animals $[28,29]$. The VFD highlights the importance of the judicious use of antibiotics in animal agriculture and demands the development of natural, safe, environmentally-friendly intervention strategies against deadly foodborne pathogens, including Salmonella [28,29].

\section{Antibiotic-Resistant Salmonella in the Food Supply}

\subsection{Poultry and Poultry Products}

Antibiotic-resistant Salmonella is a significant concern in poultry production. After the approval of fluoroquinolones (enrofloxacin and sarafloxacin) in poultry husbandry in 1995, an extensive use of antibiotics started to augment poultry production. However, the reports from the National Antimicrobial Resistance Monitoring System (NARMS) presented incidences of the isolation of antibiotic-resistant Salmonella, eventually culminating in the withdrawal of major antibiotics such as fluoroquinolones from poultry production [30,31]. Interestingly, even after the withdrawal of some of these antibiotics from production, a high prevalence of Salmonella resistant to fluoroquinolones has been reported, posing a significant threat to poultry food safety and human health [2,6,32-34].

Often, farm environments are the reservoirs of pathogens, including antibiotic-resistant bacteria $[35,36]$. Recently, Salmonella isolates resistant to multiple antibiotics, including streptomycin (30.9\%), gentamicin 
$(12.6 \%)$, sulfadimethoxine $(20.9 \%)$, tetracycline $(13.9 \%)$, and trimethoprim-sulfamethoxazole combination $(8.6 \%)$ were recovered from broiler farms. Among these isolates, $20 \%$ were resistant to three or more antibiotics; $67 \%$ of $S$. Heidelberg and $54 \%$ of $S$. Kentucky isolates showed resistance to five or more antibiotics [37]. In addition to a high prevalence of $S$. Enteritidis noticed in hatching eggs, litter, feed, drinkers, bird rinse, and ceca, $88 \%$ of $S$. Enteritidis were reported to be resistant to multiple drugs including ampicillin, nalidixic acid, and tetracycline [32].

Currently, intervention strategies are practiced at the farm level to control antibiotic-resistant Salmonella in poultry and its spread to carcasses during processing. However, antibiotic-resistant strains of Salmonella serovars such as $S$. Enteritidis, $S$. Infantis, $S$. Typhimurium, and $S$. Heidelberg have frequently been isolated from broiler carcasses [38]. Augusto et al. [38] reported high resistance of the aforementioned isolates towards ceftriaxone (75\%) and ceftiofur (44\%). Recently, a Canadian study reported a significant correlation between the isolation of ceftiofur-resistant $S$. Heidelberg from retail chicken meat and the incidence of human clinical infections with S. Heidelberg during 2003-2008 [39]. Another study conducted by Duiy et al. [40] revealed a high prevalence of antibiotic-resistant Salmonella in poultry meat compared to beef and lamb samples, and observed $S$. Bredeney, $S$. Kentucky, and $S$. Enteritidis as major serotypes isolated from poultry meat. These serotypes showed high resistance to antibiotics such as rifampicin, tetracycline, oxytetracycline, and sulphamethoxazole. Also, ceftiofur and ceftriaxone-resistant Salmonella were isolated from ground chicken and turkeys [41].

Antibiotic-resistant Salmonella has been isolated from retail meats as well. For example, sampling from poultry retail outlets of Pennsylvania during 2006-2007 showed contamination of $22 \%$ of meat samples with Salmonella. Among the different Salmonella isolates, 31\% were resistant to three antibiotics, and $21 \%$ were resistant to ceftiofur. In addition, one ceftiofur-resistant $S$. Typhimurium showed an indistinguishable pulse field gel electrophoresis (PFGE) pattern with a human isolate [42]. Along with this, sampling of whole chicken carcass from the retail outlets [33] revealed a high prevalence of Salmonella (25\%). Among these, $40 \%$ of isolates were resistant to multiple antibiotics ( $\geq 4$ antibiotics), $70 \%$ were resistant to at least one antibiotic, and $52 \%$ isolates showed increased resistance to ciprofloxacin. Another study conducted in retail meats revealed Salmonella isolates with high resistance to common antibiotics. Among the different isolates, $82 \%$ showed resistance to at least one antibiotic, and the increased resistance observed was against tetracycline (68\%), streptomycin (61\%), sulfamethoxazole (42\%), and ampicillin (29\%) [43]. Also, 9\% of the Salmonella isolates showed resistance to ceftriaxone. Another study conducted by Parveen and co-workers [44] revealed the presence of antibiotic-resistant Salmonella isolates from poultry chiller water and carcasses. The isolated Salmonella spp. were resistant to antibiotics including tetracycline, ampicillin, amoxicillin-clavulanic acid, ceftiofur, streptomycin, and sulfisoxazole [44]. Recently, the FDA published the NARMS retail meat interim report for Salmonella, which includes the antibiotic resistance profile of Salmonella spp. in retail poultry meat [34].

The intense use of antibiotics in conventional farms has promoted resistance development in Salmonella spp. [45]. Sapkota et al. [45] reported that when a conventional farm was converted to an organic farm, the prevalence of the antibiotic-resistant Salmonella was reduced. The Salmonella isolates, including $S$. Kentucky from the organic production facility, showed significantly lower resistance to antibiotics such as amoxicillin-clavulanate, ampicillin, cefoxitin, ceftiofur, and ceftriaxone. Among the S. Kentucky isolates, only $6 \%$ from the organic farm showed multiple antibiotic resistance whereas $44 \%$ of isolates from conventional farms showed multiple antibiotic resistance [45]. A study conducted by Alali et al. [17] also reported a high prevalence rate of Salmonella in fecal and feed samples in conventional farms compared to the certified organic facilities when the chickens were 3 and 8 weeks old. The population of resistant bacteria was higher from the conventional farm, where the resistance to a single antibiotic and two or more antibiotics was $36.2 \%$ and $62 \%$, respectively. The isolates showed high resistance to ampicillin, streptomycin, amoxicillin-clavulanic acid, cephalothin, ceftiofur, and cefoxitin. When a comparison of Salmonella isolates obtained from organic and conventional poultry samples from Maryland retail stores was made, all S. Typhimurium isolates (12 isolates; $100 \%$ ) 
obtained from conventional carcass samples were resistant to between five and seven antimicrobials, whereas $79 \%$ of the $S$. Typhimurium isolates (15 out of 19 total isolates) from organic carcass samples showed susceptibility to all 17 tested antimicrobials [46].

\subsection{Cattle and Beef}

Antibiotic-resistant Salmonella has also been isolated from beef cattle. A study conducted in the USA reported a high prevalence of Salmonella from hide and feces swab samples $(70 \%$ and $30 \%$, respectively) from cattle nearing their market age. Among the Salmonella enterica isolates, $33.1 \%$, $8.35 \%, 3.75 \%$, and $3.75 \%$ of isolates were resistant to one, two, three, and four or more antibiotics, respectively. Resistance to sulfisoxazole (39.5\% of isolates), tetracycline $(10.9 \%)$, and ampicillin $(8.89 \%)$ was common. However, ceftriaxone resistance was also detected in two isolates [47]. A recent study by Schmidt et al. [48] evaluated the presence of antibiotic-resistant Salmonella from production to processing continuum by sampling feces, hides, carcass, and strip loins. Third-generation cephalosporin-resistant Salmonella was detected in $0.5 \%$ of fecal samples and $10.9 \%$ of hide samples from feedlots. In addition, prevalence rates of $1.6 \%$ and $7.6 \%$ cephalosporin-resistant Salmonella were observed during processing from fecal and hide samples, respectively. However, none of the pre-eviscerated carcasses, final carcasses, or strip loin samples were found to be positive for antibiotic-resistant Salmonella, which indicates the effectiveness of sanitation procedures during processing in preventing the hide-to-carcass transfer of antibiotic-resistant Salmonella. However, Salmonella can harbor in bovine peripheral lymph nodes such as subiliac lymph nodes, which are often protected from the carcass sanitation procedures and pose potential threats when adipose trim containing lymph nodes are incorporated into the ground beef [49]. A cross-sectional study conducted by collecting subiliac lymph nodes $(n=3327)$ from feedlot cattle at harvest revealed a $11.8 \%$ prevalence rate of Salmonella enterica isolates, with S. Montevideo and $S$. Anatum as major serovars. Among these, $8.3 \%$ were resistant to multiple antibiotics including ampicillin, chloramphenicol, streptomycin, sulfisoxazole, tetracycline, amoxicillin/clavulanic acid, ceftiofur, and ceftriaxone [49].

Ground beef also carries antibiotic-resistant Salmonella. A study conducted by White et al. [41] revealed a Salmonella prevalence rate of approximately $6 \%$ in ground beef samples, and the isolated $S$. Typhimurium strains were highly resistant to ceftiofur and ceftriaxone. In another study, Salmonella serovars such as S. Typhimurium, S. Lille, S. Montevideo, S. Hadar, S. Meleagridis, S. Cerro, S. Kentucky, or $S$. Muenster were identified from ground beef samples collected from 404 retail stores. Among these, five $S$. Typhimurium isolates were resistant to ampicillin, streptomycin, sulfamethoxazole, ticarcillin, and tetracycline [50]. Recently, the FDA published the NARMS retail meat interim report for Salmonella that includes the antibiotic resistance profile of Salmonella spp. in retail beef products [34]. According to the report, 38.5\% of the Salmonella spp. isolated from ground beef in 2014 showed resistance to ceftriaxone and were resistant to three or more classes of antibiotics. In addition, the genes conferring resistance to major classes of antibiotics such as aadB, $\operatorname{str} A / \operatorname{str} B$, blaCMY, sul2, blaTEM, floR, cmlA, gyrA mutation, tet $A$, tet $B$, or tet $C$ were detected in Salmonella isolates from ground beef. The role of these genes in conferring antimicrobial resistance in Salmonella is described later in this review [34].

The presence of multidrug-resistant Salmonella in dairy cattle is also a significant threat to food safety. A study conducted by Cobbold et al. [51] revealed a prevalence rate of $32 \%$ Salmonella in dairy farms, with a high prevalence for multidrug-resistant $S$. Newport. In addition, the persistent excretion of Salmonella in cows (for 190 days) often resulted in the contamination of farm environments such as bedding materials, feed refusals, lagoon slurry, and milk filters. In a different study, Rodriguez-Rivera et al. [52] reported the prevalence of Salmonella serovars such as S. Cerro, S. Kentucky, $S$. Typhimurium, and $S$. Anatum along with $S$. Newport in dairy cattle and farm environments. The same study reported that $23.6 \%$ of isolates were resistant to clinically-important antibiotics with 50 different resistance patterns, including 12 serovars showing indistinguishable PFGE patterns with human isolates, indicating the reservoir status of subclinically infected dairy cattle as a source of human 
salmonellosis. The most common resistance observed was to antibiotics such as ampicillin (72\% of the isolates), tetracycline (63\% of the isolates), and amoxicillin/clavulanic acid (58\% of the isolates). Among the different Salmonella serovars, $S$. Typhimurium showed the highest resistance to the tested antibiotics, and $S$. Typhimurium isolates alone showed 20 different resistance patterns. The antibiotic resistance observed with the different serovars was in the following order: $S$. Typhimurium $>S$. Cerro $>$ S. Newport $>$ S. Kentucky.

Studies have also revealed that the dairy herds (93 herds) in the northeastern U.S. have a Salmonella prevalence rate of $22.5 \%$, with a high incidence rate for $S$. Newport $(41 \%)$ and $S$. Typhimurium. The isolates showed higher resistance to clinically important drugs such as ampicillin $(68.8 \%)$, ceftiofur $(60.4 \%)$, chlortetracycline $(66.8 \%)$, florfenicol $(63.7 \%)$, neomycin $(42.2 \%)$, oxytetracycline $(68.9 \%)$, and sulfadimethoxine (79.3\%). Among the different isolates, $S$. Newport (97\% isolates), S. Typhimurium (Copenhagen) ( $98.4 \%$ of isolates), and S. Agona ( $83.3 \%$ of isolates) showed resistance to five or more antibiotics [53]. S. Typhimurium isolates from cattle were found to be associated with Salmonella infection in humans, and were resistant to ampicillin, sulfisoxazole, kanamycin, and streptomycin, as well as to broad-spectrum cephalosporins, aztreonam, cefoxitin, gentamicin, and tobramycin [54].

\subsection{Swine}

Similar to poultry, antibiotic usage started in swine production as early as the 1950s. Antibiotics including tetracycline, sulfonamides, and bacitracin were commonly used in swine production to increase the production performance or as therapeutic agents. Also, antibiotics were found to be an effective remedy against mortality and morbidity in young pigs and piglets to diseases [55]. Ever since the introduction of antibiotics, the extensive use of antibiotics has resulted in the development of resistance in human pathogens, including Salmonella in swine $[18,19,56]$. Both swine-adapted and non-swine-specific serovars of Salmonella developed antibiotic resistance [57]. S. cholerasuis is a swine-adapted serovar of Salmonella that causes severe invasive infections in humans, and often requires antibiotic treatment. This particular serovar developed antibiotic resistance against clinically important drugs as evidenced by a study conducted by Lynne et al. [58]. The results of the study revealed that $87.5 \%$ of swine isolates of $S$. cholerasuis were resistant to at least one antibiotic, whereas $37.5 \%$ showed resistance to four or more antibiotics. The most common resistance pattern observed was against tetracycline, ampicillin, streptomycin, and sulfisoxazole [58]. The resistance development in S. cholerasuis is a serious concern, since $52 \%$ of culture-confirmed cases of S. cholerasuis are linked with human infections [59]. Furthermore, the population dynamics of antibiotic-resistant Salmonella serovars vary in swine due to the varying selection pressure exerted by the different antibiotics [57]. Therefore, a constant monitoring system is required to detect the prevalence of antibiotic-resistant Salmonella in swine production.

Multidrug-resistant Salmonella has been identified from intensive and extensive rearing systems in swine herds. High resistance profiles against tetracycline $(78.5 \%)$ and streptomycin $(31.5 \%)$ have been reported when environmental and carcass swabs from extensive and intensive poultry farming facilities were sampled. Among the different serovars, $S$. Typhimurium var. Copenhagen showed resistance against ampicillin, chloramphenicol, streptomycin, sulfamethoxazole, and tetracycline [19]. Similarly, Gebreyes et al. [18] also reported antibiotic-resistant Salmonella isolates in conventional farms compared to antibiotic-free non-conventional farms with high resistance to tetracycline (80\%).

Baggesen and Aarestrup [60] reported multiple-antibiotic-resistant Salmonella from swine herds. Among the 670 isolates, $34 \%$ were resistant to streptomycin, and $17 \%$ were resistant to tetracycline. In addition, multidrug-resistant $S$. Typhimurium DT104 was isolated from the swine herds conferring resistance to spectinomycin, streptomycin, and sulphonamides. Similarly, Perron et al. [61] reported that Salmonella serovars from pigs were resistant to common antibiotics and $65 \%$ of isolates showed resistance to tetracycline, whereas $25 \%$ of all isolates were multidrug resistant. Moreover, $90 \%$ of S. Typhimurium DT104 were resistant to 2 or more antibiotics. In this study, the detected antibiotic 
resistance was in the following order: tetracycline $>$ ampicillin $>$ chloramphenicol $>$ neomycin $>$ trimethoprim-sulfa combination.

Similar to poultry and cattle, antibiotic-resistant Salmonella were isolated from feces, cecal contents, and mesenteric lymph nodes of pigs, and in environmental samples such as barn floor, lagoon, barn flush, trucks, and holding pens [24]. Multidrug resistance patterns such as AxACSSuT (amoxicillin-clavulanic acid, ampicillin, chloramphenicol, streptomycin, sulfamethoxazole, and tetracycline) and AKSSuT (ampicillin, kanamycin, streptomycin, sulfamethoxazole, and tetracycline) were common in $36 \%$ and $45 \%$ of the $S$. Typhimurium isolates from swine feces, respectively [24]. Also, high resistance to tetracycline $(85 \%)$, ampicillin (47\%), amoxicillin-clavulanic acid (23\%), and chloramphenicol (21\%) was reported in the same study [62]. Another serovar of Salmonella, S. Muenchen, was also identified from pigs, and $75 \%$ of the isolates showed AKSSuT-type resistance [63]. Also, improperly decontaminated swine manure application was found to be another important source of dissemination and persistence of antibiotic-resistant Salmonella in the environment. High frequency of resistance against streptomycin $(88.36 \%)$, sulfisoxazole $(67.2 \%)$, and tetracycline $(57.67 \%)$ was identified in swine manure samples [56].

Antibiotic-resistant Salmonella has frequently been isolated from retail pork products. Pork chops and pork ribs carrying antibiotic-resistant Salmonella containing blaCMY (gene encoding $\beta$-lactam resistance) has been identified [64]. Recently, the FDA published the NARMS retail meat interim report for Salmonella that includes the antibiotic-resistance profile of Salmonella spp. in retail pork products [34].

\subsection{Fresh Produce}

Antibiotic-resistant pathogens have also been isolated from fresh produce, although it is less frequent as compared with that recovered from food animals. The U.S. domestic market has a high demand for fresh produce. Billions of dollars worth of fresh produce, fruits, and vegetables are exported from ( $\$ 7$ billion) and imported to ( $\$ 18$ billion) the U.S. [65]. Fresh produce such as leafy greens, herbs, and spinach in retail stores are often contaminated with coliform bacteria. Aerobic plate counts as high as 6-7.4 $\log _{10} \mathrm{CFU} / \mathrm{g}$ and a coliform count ranging from 0 to $>8.5 \log _{10} \mathrm{CFU} / \mathrm{g}$ have been reported previously [66]. On the other hand, recent studies have revealed a low prevalence of Salmonella in fresh produce [26,66]. Liu and Kilonzo-Nthenge [26] reported that the prevalence of Salmonella in fresh produce from the U.S. chain markets (a total of 360 fresh produce samples; 129 imported and 231 U.S.-grown) was $0.3 \%$, whereas $0.8 \%$ fresh produce imported to the U.S. was positive for Salmonella. The antibiotic resistance was reported in Salmonella isolates recovered from imported fresh produce (1.9\% of the isolates). The majority of them showed resistance to ampicillin-erythromycin-kanamycin (AEK) and streptomycin-vancomycin (SV) resistance patterns [26].

Environmental contamination may have a direct relationship to the presence of antibiotic-resistant Salmonella in fresh produce. For example, studies by Duffy et al. [67] indicated Salmonella prevalence in irrigation water, packing shed equipment, and fresh produce from two different produce farms. Among these, $20 \%$ of the Salmonella isolates showed intermediate resistance to streptomycin. Similarly, Salmonella isolates from cantaloupes showed resistance to streptomycin. Irrigation water is also a source of the contamination of fresh produce with Salmonella. Salmonella serovars such as S. Newport, $S$. Enteritidis, S. Muenchen, S. Javiana, and S. Thompson have been isolated from ponds in fresh produce farms. S. Newport was resistant to multiple antibiotics, and some of them showed PFGE patterns identical to human isolates obtained from clinical settings. S. Newport isolates showed resistance to ampicillin, chloramphenicol, streptomycin, sulfamethoxazole, and tetracycline (ACSSuT) and also to cephalothin, ceftriaxone, and amoxicillin-clavulanic acid [68].

The intrusion of wild animals into crop fields often introduces pathogens, especially antibiotic-resistant clones, posing a threat to food safety. A prevalence study conducted on the feces of stray dogs and coyotes (461 fecal samples) collected from the leafy green fields at the U.S.-Mexico border revealed a Salmonella prevalence rate of $9 \%$ and $32 \%$ in dog and coyote fecal samples, respectively. Among Salmonella isolates, $12 \%$ were resistant to at least one antibiotic, and $6 \%$ 
were resistant to two or more antibiotics. S. Newport isolated from coyote fecal samples showed antibiotic resistance to multiple drugs, such as ampicillin, amoxicillin/clavulanic acid, ceftriaxone, chloramphenicol, and trimethoprim/sulfamethoxazole [69]. Wild amphibians and reptiles associated with surface waters in crop-producing regions can also act as a source of pathogens on fresh produce. Among the 460 amphibians and reptiles sampled, 37 were found to harbor Salmonella, with snakes having a high prevalence rate of $59 \%$. In addition, $12.6 \%$ of the water samples were positive for Salmonella. In the same study, PFGE revealed the occurrence of similar Salmonella strains in water and animal samples. Among the 66 total Salmonella isolates, 23 were resistant to more than one class of antibiotics, whereas six isolates were resistant to three classes of antibiotics. S. enterica subspecies IIIb 38:1, v:Z $\mathrm{Z}_{53}$ from snake was the most resistant isolate, and showed resistance to amikacin, gentamicin, streptomycin, cephalothin, and ampicillin. In addition, the isolated S. enterica subspecies IIIa and IIIb were previously associated with human illnesses [70]. The domestic animals are also involved in the environmental contamination with antibiotic-resistant Salmonella, and subsequently contaminate vegetables. For example, dairy and beef cattle can excrete Salmonella through their feces, which can contaminate the crops when used as manure without appropriate treatments [47,48,71]. Therefore, the role of domestic species and wild animals in serving as reservoirs of antibiotic resistance clones to crops and vegetables needs to be explored to provide the scientific basis for effective preventative measures.

Recently, drug-resistant S. Poona caused a multistate outbreak in the U.S. involving 40 states due to the consumption of contaminated garden cucumber, resulting in 204 hospitalizations and six deaths during 2015-2016. Among the isolates that were identified as etiological agents, two were resistant to antibiotics. One isolate was resistant to tetracycline, and the other was resistant to nalidixic acid and ciprofloxacin [6]. The outbreak investigation could not determine an association of the illness with cross-contamination within the distribution chain, including shipping containers or retail outlets. Therefore, the presence of antibiotic-resistant Salmonella in fresh produce and its association with foodborne outbreaks warrants stricter surveillance and targeted interventions.

\subsection{Seafood}

Seafood is also a commonly implicated vehicle for the transmission of antibiotic-resistant bacteria [72-74], and imported seafood in the U.S. contributes to more than $80 \%$ of the supply. Foodborne pathogens such as Salmonella, Listeria monocytogenes, Campylobacter, and E. coli have been isolated from imported seafood [75]. A study conducted in the U.S. revealed the prevalence of antibiotic-resistant Salmonella $(24 \%)$ in imported seafood. The same study identified $S$. Newport, $S$. Typhimurium var. Copenhagen and $S$. Lansing with resistance to multiple antibiotics, including trimethoprim-sulfamethoxazole combination, sulfisoxazole, tetracycline, streptomycin, and spectinomycin. Among the different isolates, $6 \%$ were resistant to more than two antibiotics [73]. Another study reported that the presence of antibiotic resistance was higher in farm-raised shrimps as compared to wild-caught shrimps. In farm-raised shrimps, $9.8 \%, 3.6 \%$, and $10.5 \%$ of Salmonella isolates showed reduced susceptibility to the antibiotics such as ceftriaxone, chloramphenicol, and tetracycline, respectively whereas, in wild-caught shrimps, 2.8, 1.4 and $1.1 \%$ bacterial isolates showed reduced susceptibility to these antibiotics. One Salmonella isolate from farm-raised shrimps was resistant to multiple antibiotics, including ampicillin, ceftriaxone, gentamicin, streptomycin, and trimethoprim [76].

Similarly, a study conducted in oysters harvested from U.S. bays revealed the prevalence of Salmonella $(7.4 \%)$, with S. Newport as the major serovar. Most of the Salmonella isolates from oysters were resistant to ampicillin and tetracycline [74]. In addition to raw sources, ready-to-eat (RTE) shrimp is one of the vehicles for spreading antibiotic-resistant Salmonella. A study by Dur et al. [77] revealed that RTE shrimps contained Salmonella as an adulterant and the isolated strains were less susceptible to commonly used antibiotics. The RTE shrimps could be contaminated with Salmonella during post-processing steps such as thawing [77]. Furthermore, a recent multistate outbreak of $S$. 
Paratyphi B and S. Weltevreden was reported in the U.S. in 2015 involving 11 states, affecting 65 people, and causing 11 hospitalizations. The infection was linked to contaminated frozen raw tuna. Among the Salmonella isolates, 33\% showed resistance to ampicillin. However, others were pan-susceptible [78].

\section{Mechanisms of Antibiotic Resistance in Salmonella and Public Health Implications}

The horizontal transmission of resistance genes plays a vital role in the dissemination of antibiotic resistance in Salmonella enterica species. These resistance genes can be found in the resistant plasmids or within the chromosome of bacteria. The horizontal transmission of genes mediated by plasmids is the most efficient method of resistance transfer, and is occurring at high frequency involving different resistance genes at a time [79]. The resistant genes that are acquired by plasmids, integrons, or transposons are capable of transferring resistance to other strains or other species. Transposons are the mobile genetic elements that can carry resistance genes and possess transposase activity providing the recombination of resistance genes with plasmids or the chromosome. Integrons consist of integrase (a recombination enzyme encoded by the intI gene), a recombination site recognized by integrase, and a promoter which are necessary for the expression of gene cassettes present in the integron [80]. These arrangements efficiently promote the acquisition of exogenous genes such as antibiotic-resistant genes in the bacterial genome, especially in plasmids. Furthermore, the conjugation events facilitate the spread of resistance genes present in plasmids through transposon or integron to other strains or species [79].

The emergence of $S$. Typhimurium definitive type (DT)104 as a multidrug-resistant pathogen was a significant issue in animal agriculture. It was first isolated from the United Kingdom, and since then it has been associated with monogastric animals and ruminants, causing foodborne outbreaks through meat and meat products. The chromosomally encoded resistance to $\geq 5$ antibiotics, including ampicillin, chloramphenicol, florfenicol, streptomycin, sulfonamides, and tetracyclines, makes this phage type challenging to tackle. The trimethoprim resistance in S. Typhimurium DT104 has been found to be associated with mobile non-conjugative plasmids [81].

The resistance of non-typhoidal Salmonella to fluoroquinolones is of particular concern since it is the drug of choice to treat invasive salmonellosis in adults. The fluoroquinolone resistance was previously linked to multiple mutations (e.g., amino acid substitutions) in quinolone resistance-determining regions (QRDRs) of the genes that code for gyrase (gyrA and gyrB) and topoisomerase IV, which are the targets for fluoroquinolones in bacterial cells. The mutation of these genes results in resistance to fluoroquinolones [81,82]. Also, the presence of an active efflux pump was reported in $S$. Typhimurium as a mechanism of antibiotic resistance. The overproduction of AcrAB (inner membrane transporter)-TolC (outer membrane transporter)-type efflux pump and associated alterations in outer membrane proteins and lipopolysaccharides synergistically caused less accumulation of ciprofloxacin in S. Typhimurium, and showed increased resistance in Salmonella. However, efflux pump blockers significantly increase the susceptibility (16-32 times) of Salmonella to fluoroquinolones [81,83].

Plasmid-mediated quinolone resistance (PMQR) genes are also involved in resistance build-up in Salmonella. PMQR genes such as oq $x A B$ and aac $\left(6^{\prime}\right)-I b-c r$ are isolated with high frequency ( $44 \%$ and $89 \%$; $o q x A B$ and $a a c\left(6^{\prime}\right) I b-c r$, respectively) from ciprofloxacin-resistant clinical isolates of $S$. Typhimurium. These PMQR genes along with gyrA mutations increase the minimum inhibitory concentration of ciprofloxacin by four-fold in S. Typhimurium. Among other PMQRs, qnr type genes also bind to DNA gyrase and topoisomerase and prevent the action of fluoroquinolones. Another PMQR gene, qepA, is associated with efflux pump and excretes fluoroquinolones to the extracellular space. However, further studies are needed to establish their prevalence in non-typhoidal Salmonella [84]. As mentioned, the AcrAB-TolC efflux system and its regulatory genes such as marRAB and soxRS are found to be involved in fluoroquinolone resistance which increased the minimum inhibitory concentration (MIC) of fluoroquinolones to $\geq 32 \mu \mathrm{g} / \mathrm{mL}$ in S. Typhimurium phage type DT204 [85] and the inactivation of the efflux pump resulted in a 16-32-fold reduction of the MIC of S. Typhimurium phage type DT204 to 
ciprofloxacin [86]. Therefore, the resistance of non-typhoidal Salmonella to fluoroquinolones is often attributed to a combination of mechanisms [87].

Non-typhoidal Salmonella spp. showing resistance to extended-spectrum cephalosporins, including ceftriaxone, is a serious concern, since these are the drugs of choice for treating invasive non-typhoidal salmonellosis in children. One of the major mechanisms of developing resistance against $\beta$-lactam antibiotics in bacteria is the direct inactivation of antibiotics by enzyme hydrolysis [88]. The production of extended spectrum $\beta$-lactamases (ESBLs) is a major mechanism conferring resistance in most of the Enterobacteriaceae. Many types of ESBLs are present based on the substrate and inhibitor mechanisms [89]. The first $\beta$-lactamase identified was TEM-1 found in an E. coli strain isolated from a patient named Temoniera in Greece [90]. TEM-1 hydrolyzes penicillins and first-generation cephalosporins. A single amino acid substitution to TEM-1 leads to a TEM-2 derivative having the same substrate as that of the TEM- 1 . The first TEM-type $\beta$-lactamase that demonstrated ESBL characteristics was TEM-3 [89]. The TEM-type $\beta$-lactamases are reported in Salmonella spp. [91,92]. Another $\beta$-lactamase, SHV (sulphydryl variable) is a plasmid-encoded $\beta$-lactamase usually found in Klebsiella pneumoniae and E. coli [90]. The TEM and SHV types of $\beta$-lactamases are most common, and are widely distributed in nature with more than 90 types of TEM and more than 25 types of SHV [90,92].

Recently, the emergence of plasmid-mediated ESBLs, namely CTX-M, is of significant concern since it is commonly found in Salmonella spp. and associated with cefotaxime hydrolysis. The horizontal transfer of CTX-M ESBL genes via conjugation plasmids and transposons are the main process involved in the acquisition of CTX-M ESBLs. The expansion of CTX-M-type $\beta$-lactamase has not been explored much, and has been different from TEM- and SHV-type $\beta$-lactamases where the amino acid substitutions are common [89]. However, it has been suggested that serine residue present at position 237 in all CTX-M type enzymes plays a role in displaying extended-spectrum antibiotic resistance [93]. In Salmonella, most of the ESBLs (e.g., blaTEM-1 and blaSHV-1 gene derivatives), including enzymes conferring resistance to third-generation cephalosporins such as blaCTX-M and blaSHV -5 , are encoded on transferable plasmids that pose a serious threat to current antibiotic treatment strategies in humans [79].

Another class of $\beta$-lactamases is the OXA type that confers resistance to ampicillin and cephalolecithin and also possesses strong hydrolytic activity against oxacillin and cloxacillin [94]. OXA-48 carbapenemase-producing Salmonella (S. Kentucky) and OXA-1 encoding poultry isolates have been identified [91,95]. PER-type ESBLs (first discovered in Pseudomonas aeruginosa strains) hydrolyzing penicillins and cephalosporins have also been reported in non-typhoidal Salmonella [96]. In addition, intrinsic cephalosporinases such as AmpC-type $\beta$-lactamases are also common in non-typhoidal Salmonella which includes enzyme types such as CMY, DHA, and ACC-1 [81,96]. Moreover, Salmonella serovars exhibiting different $\beta$-lactamases such as CMY-7, SHV-9, and OXA-30 were also identified [97], indicating the possession of a high level of cross-resistance by non-typhoidal Salmonella serovars.

Aminoglycoside-modifying enzymes mainly mediate resistance to aminoglycoside antibiotics. The aminoglycoside acetyltransferases modify amino groups in aminoglycoside antibiotics. The genes encoding aminoglycoside acetyltransferases are named as aac, and are typically located in Salmonella genomic islands, integrons, and plasmids. These acetyltransferases provide resistance to major antibiotics such as gentamicin and kanamycin. In addition, aminoglycoside hydroxyl group phosphorylating enzymes, namely aminoglycoside phosphotransferases, are involved in resistance development against aminoglycoside antibiotics in Salmonella. These enzymes are encoded by the genes $\operatorname{str} A, \operatorname{str} B, a p h(3)-I b$ and $a p h(6)-I d$, respectively) and provide resistance to streptomycin. Some of the aminoglycoside phosphotransferases also provide resistance to kanamycin and neomycin. Nucleotidyltransferases are also hydroxyl group-modifying enzymes present in Salmonella and are often encoded in aad genes. Among the different varieties of aminoglycoside adenylyltransferase coding genes, aadA provides resistance to streptomycin whereas aadB provides resistance to gentamicin and tobramycin in Salmonella [98]. 
Tetracycline resistance is mainly developed in Salmonella due to the acquisition of genes that code for energy-dependent efflux mechanisms [98]. Mainly tet genes are involved in efflux mechanisms, and confer resistance to chlortetracycline, doxycycline, oxytetracycline, and tetracycline [99]. Among these, $\operatorname{tet}(A)$ is common. However, others such as tet $(B), \operatorname{tet}(C)$, tet $(D), \operatorname{tet}(G)$, and $\operatorname{tet}(H)$ have been reported in non-typhoidal Salmonella from clinical or retail meat isolates [98,100]. The tet $(A)$ genes have been found in plasmids, integrons, and genomic island 1 . The tet $(B)$ are detected in transferable plasmids. The tet $(A)$ genes are detected in Salmonella serovars such as S. Agona, S. Dublin, S. Choleraesuis, S. Heidelberg, and $S$. Typhimurium [98]. In addition to this, ribosomal protection proteins such as tet( $M)$, tet $(O)$, tet $(S), \operatorname{tet}(W)$, and tet (32) prevent the ribosomes from the action of tetracyclines in microorganisms. Some genes encode enzymes such as tet $(X), \operatorname{tet}(34)$, and tet (37) which modify or inactivate the action of tetracyclines. However, the efflux mechanisms are more common [99].

The resistance development in microorganisms against phenicol antibiotics including chloramphenicol and florfenicol is mainly by two mechanisms involving efflux pumps or enzymatic inactivation of antibiotics by chloramphenicol O-acetyltransferase. The chloramphenicol O-acetyltransferase enzymes are not capable of inactivating florfenicol since the fluorinated c3 position in florfenicol does not accept acetyl groups. The genes encoding chloramphenicol O-acetyltransferases are referred to as cat genes and are often associated with plasmids. The cat 1 and cat 2 genes have been isolated from non-typhoidal Salmonella serovars. The cat genes are associated with plasmids, transposons, or gene cassettes and other mobile genetic elements [101]. Genes such as $\mathrm{cmlA}$ and floR encode the efflux pumps in Salmonella isolates. The floR genes are widely distributed among the Salmonella serovars and are found to be associated with transferable plasmids and Salmonella genomic islands [98].

The sulfonamide resistance in Salmonella is due to the presence of the sul gene, which causes the expression of an insensitive form of dihydropteroate synthetase that cannot be inhibited by sulfonamides. The common sul genes are sul1, sul2, and sul3, which have been identified from major Salmonella serovars, including $S$. Enteritidis, $S$, Typhimurium, $S$. Heidelberg, and $S$. Hadar. These genes are present in integrons, Salmonella genomic islands, or transferrable plasmids [98,102]. The dhfr genes cause the expression of an insensitive form of dihydrofolate reductase (DHFR) that cannot be inhibited by trimethoprim antibiotics and lead to the development of resistance against this class of antibiotics in Salmonella. These genes are also associated with integrons, plasmids, or Salmonella genomic islands [98,102].

\section{Antibiotic Alternatives against Salmonella}

Not many interventions have targeted antibiotic-resistant Salmonella. Although it is generally understood that the interventions used against the non-antibiotic-resistant bacteria could work equally well against resistant Salmonella, this area needs further exploration. Given below are the potential interventions that could be used to target antibiotic-resistant Salmonella. The interventions explained here are mostly targeted to control antibiotic-resistant Salmonella colonization in food animals and poultry for improving the preharvest microbiological safety with some directions for potential postharvest applications.

\subsection{Direct Fed Microbials (DFMs)}

Interventions using DFMs and probiotic bacteria are getting widespread support due to the current issues associated with antibiotic resistance and the emergence of organic production as a significant contributor to the domestic and international markets $[103,104]$. Probiotics, including DFMs, are used/tested to maintain balanced microbial ecology in the gut [105], enhance the production performance of livestock, and as potential antimicrobials against pathogenic bacteria [106]. Probiotics such as B. subtilis, Lactobacillus strains, Saccharomyces (probiotic yeast), and Aspergillus oryzae have antimicrobial properties against pathogenic bacteria including Salmonella spp. [104,107-109], and among these, Lactobacillus strains are being generally used in animal agriculture [110]. 
Different strains of Lactobacillus species are commonly used in poultry to reduce cecal colonization of Salmonella and its fecal shedding. Spray application and drinking water supplementation of a Lactobacillus-based probiotics were also found to be effective in reducing $S$. Enteritidis colonization in cecal tonsils in broiler chicks [111]. A study conducted by Higgins et al. [112] revealed that the oral administration of Lactobacillus spp. at concentrations of $10^{6}$ and $10^{8} /$ chick resulted in significant reduction of $S$. Enteritidis after experimentally challenging the neonatal broiler chicks with $10^{4} \mathrm{cfu} S$. Enteritidis orally. The recovery rate of Salmonella in the treatments was $15 \%$, whereas a higher recovery of $85 \%$ was obtained in the control group. Another study conducted by Menconi et al. [113] described the efficacy of a Lactobacillus-based probiotic, namely FloraMax, in reducing the cecal colonization of $S$. Heidelberg after 24 and $72 \mathrm{~h}$ post-infection in experimentally challenged chicks and poults. Also, studies showed that Lactobacillus salivarius CTC2197 could eliminate $S$. Enteritidis from chickens after an oral challenge of the pathogen on day 1 [114]. Some strains of Bacillus subtilis were found effective against $S$. Enteritidis attachment and invasion of intestinal epithelial cells [115].

In swine, DFM supplementation was found to be effective against Salmonella. A combination of Bifidobacterium longum subsp. infantis and B. animalis subsp. lactis resulted in reduced colonization of $S$. Typhimurium in weaned piglets. The DFM combination resulted in improved intestinal health and reduced the fecal shedding of Salmonella after 4 and 8 days post-challenge [116]. Prophylactic administration of L. rhamnosus GG reduced S. Infantis-induced diarrhea and intestinal inflammation in piglets [117]. A study conducted by Yin et al. [118] revealed that Lactobacillus-fermented feed significantly reduced intestinal colonization of $S$. Typhimurium DT104 and associated diarrhea in pigs and reduced the invasion of Salmonella to the spleen. Also, some marine isolates of Bacillus strains possessed excellent probiotic qualities and Salmonella inhibition activities. These strains could be potential probiotics for livestock [119]. Similar to poultry and swine, DFMs such as P. freudenreichii, L. animalis, L. acidophilus, L. casei, L. salivarius, and, Pediococcus acidilactici were found to be effective against major serovars of Salmonella colonizing in cattle, including S. Dublin [120-122].

\subsection{Prebiotics}

Prebiotics are non-digestible carbohydrate substrates that selectively promote the growth of most of the beneficial or probiotic microflora when supplemented in the diet [123]. These fermentable carbohydrates mainly act in the lower intestine, resulting in the production of short-chain fatty acids and promote the growth of intestinal probiotic bacteria such as Bifidobacterium and Lactobacillus [124].

Studies conducted by Pourabedin et al. [125] revealed that the supplementation of mannan-oligosaccharides (MOSs) and xylo-oligosaccharides (XOSs) caused a significant reduction (1.6 and $1.0 \log _{10} \mathrm{CFU} / \mathrm{g}$, respectively) of the cecal colonization of $S$. Enteritidis. A study conducted by Fernandez et al. [126] revealed that $2.5 \%$ dietary supplementation of MOS resulted in reduced colonization of Salmonella spp. in the cecum of chicks. Supplementation of arabinoxylan oligosaccharides resulted in reduced colonization of $S$. Enteritidis in the cecum of broilers, and the supplementation also resulted in reduced shedding of the pathogen through the feces [127].

Similar to poultry, galacto-oligosaccharides and polysaccharides derived from seaweeds have been found to enhance the intestinal health of pigs when challenged with $S$. Typhimurium. The $S$. Typhimurium numbers were less in the cecum, colonic digesta, and fecal samples when the pigs were supplemented with seaweed-derived polysaccharides [128]. Another study conducted by Tanner et al. [129] also revealed that prebiotics such as fructo-oligosaccharides and galacto-oligosaccharides reduced $S$. Typhimurium in vitro when simulated with proximal colon conditions $\left(38^{\circ} \mathrm{C}, \mathrm{pH}\right.$ 6.0, retention time $9 \mathrm{~h}$, and anaerobiosis) in the pig.

Prebiotics act in different ways to bring about the desired effect in the host. Prebiotics modulate beneficial microorganisms in the gut, stimulate the host immune system, and reduce various virulence factors of the pathogen which are responsible for its colonization in the host. Prebiotics reduce pathogen attachment and invasion to the host intestinal epithelium [130]. Even though the prebiotics have a 
direct effect on the pathogens, most of the time prebiotics are used in combination with probiotics (synbiotics) to exclude pathogens in poultry and livestock.

\subsection{Plant-Derived Compounds}

There is increasing interest in the use of natural compounds as antibiotic alternatives against foodborne pathogens [131-138]. Essential oils are volatile aromatic compounds obtained from different plant parts and are effective against foodborne pathogens, including Salmonella, in vivo and in vitro [133-135,139-144]. The essential oils have different components, and thereby use multiple mechanisms against pathogens. Therefore, the potential for developing resistance to essential oils and their ingredients is highly unlikely $[145,146]$.

Plant-derived compounds such as trans-cinnamaldehyde and eugenol were found to be effective against Salmonella colonization in layer and broiler chickens $[133,134]$. Subinhibitory concentrations of trans-cinnamaldehyde and eugenol downregulated motility and invasion genes, and infeed supplementation of trans-cinnamaldehyde $(0.5 \%$ and $0.75 \%)$ and eugenol $(0.75 \%$ and $1.0 \%)$ resulted in more than $3 \log _{10} \mathrm{CFU} / \mathrm{g}$ reductions in cecal colonization of Salmonella in broiler chicks. Also, trans-cinnamaldehyde $(0.75 \%)$ and eugenol $(1 \%)$ were highly effective against $S$. Enteritidis colonization in market-age broilers [134]. In a different study, it was reported that plant-derived molecules alone or in combination increased the sensitivity of multidrug-resistant $S$. Typhimurium DT104 towards antibiotics, ampicillin, chloramphenicol, streptomycin, sulfamethoxazole, and tetracycline [147]. The pathogen was susceptible to chloramphenicol, streptomycin, sulfamethoxazole, and tetracycline when used with thymol and trans-cinnamaldehyde. Similarly, carvacrol increased the susceptibility of the pathogen to sulfamethoxazole. However, a combination of trans-cinnamaldehyde, $\beta$-resorcylic acid, carvacrol, thymol, and eugenol resulted in a higher susceptibility of the pathogen to the tested antibiotics [147]. Another plant-derived molecule, namely carvacrol, at its subtherapeutic dose was found to be effective in reducing $S$. Typhimurium motility and its invasion of porcine epithelial cells [148].

Essential oils and their ingredients are generally recognized as safe (GRAS) flavoring agents and food additives. However, their use at higher concentrations in food may negatively impact the organoleptic qualities, including flavor and odor, thereby decreasing consumer acceptance. Therefore, a delicate balance exists between the selection of an effective concentration of these compounds against pathogenic microorganisms and their use in food systems [131]. Essential oils and their ingredients are widely used in meat products and fresh produce to reduce foodborne pathogens. Carvacrol, thymol, and eugenol are found to be effective against foodborne pathogens such as Salmonella spp. when used as post-chill dip treatment alone or in combination with high-carbon dioxide packaging on turkey breast cutlets [141,142]. Similarly, carvacrol, thymol, and eugenol were effective in reducing Salmonella attached to the tomato surface [149]. Cinnamon oil (0.8-1.0\%) and olive extract (4-5\%) were effective in reducing multidrug-resistant $S$. Typhimurium DT104 in ground pork [150]. These essential oils are also effective against Salmonella in beef products [131,151,152].

\subsection{Organic Acids}

Medium- and short-chain fatty acids possess antibacterial efficacy against Salmonella spp. Short-chain fatty acids such as butyrate downregulate the invasion genes in Salmonella whereas propionate reduces Salmonella invasion [153]. A medium-chain fatty acid, caprylate (15 $\mathrm{mM})$, was found to be effective against $S$. Typhimurium in a simulated cecal environment and caused more than $4 \log _{10}$ CFU/g reduction of Salmonella [154]. Butyric acid was found to decrease intestinal colonization and fecal shedding of $S$. Typhimurium in pigs. Similarly, medium-chain fatty acids such as a caproic or caprylic acid ( $2 \mathrm{mM})$ downregulated virulence genes of $S$. Typhimurium such as hilA and fimA [155]. Short-chain fatty acids such as formic acid, acetic acid, propionic acid, and sorbic acid in combination with natural extracts were found to be effective in reducing cecal colonization and fecal shedding of Salmonella in market-age pigs [156]. 
A study conducted by Evans et al. [157] revealed that when medium-chain fatty acids were supplemented through feed, a $1 \log _{10}$ reduction in the cecal colonization of $S$. Typhimurium was observed in turkey poults 3 days after inoculation. Also, supplementation of caprylic acid at $0.7 \%$ and $1.0 \%$ significantly reduced Salmonella after 5 days of challenge in chickens $[158,159]$. A study by Van Immerseel et al. [160] also revealed that caproic acid at $3 \mathrm{~g} / \mathrm{kg}$ feed resulted in a significant reduction of Salmonella in the cecum of broilers. In these two studies, a reduction of Salmonella invasion to the liver and spleen were observed along with a reduction in the cecal colonization. Since shortand medium-chain fatty acids are effective against Salmonella and do not affect the performance of the livestock, these can be used as alternatives to antibiotics to control antibiotic-resistant Salmonella colonization in livestock species.

\section{Ongoing Studies with Alternative Interventions against Multidrug-Resistant Salmonella}

Multidrug-resistant $S$. Heidelberg is emerging as a significant pathogen causing foodborne disease outbreaks in the U.S. through contaminated poultry products. In 2011, the pathogen caused foodborne outbreaks through contaminated ground turkey products that resulted in 136 illnesses in 34 states [10]. The outbreak isolates were resistant to several commonly prescribed antibiotics, including ampicillin, streptomycin, gentamicin, and tetracycline [10,161]. In our lab, we are developing non-antibiotic interventions against this multidrug-resistant Salmonella. A dairy probiotic bacteria, namely Propionibacterium freudenreichii, was found effective against Salmonella spp., including the multidrug-resistant $S$. Heidelberg. A study conducted by Nair and Kollanoor-Johny [162] revealed that probiotic $P$. freudenreichii isolated from fermented dairy products was effective against major virulence factors of multidrug-resistant $S$. Heidelberg. Compared to the antibiotic-resistant parent strains, probiotic-treated $S$. Heidelberg showed reduced multiplication, motility, and adhesion on intestinal epithelial cells. Follow-up in vivo study revealed that supplementation of $P$. freudenreichii to 14-day turkey poults resulted in reduced pathogen colonization in the cecum [163]. Also, P. freudenreichii in combination with a mannanoligosaccharide prebiotic and a Salmonella-specific vaccine was found to be effective in reducing cecal colonization of $S$. Heidelberg in 7-week and 12-week old turkeys (unpublished data). In another study, we found that multiple combinations of probiotics (Lactobacillus of turkey-gut origin), prebiotic, and the Salmonella vaccine were effective in reducing $S$. Heidelberg colonization in the cecum of 14 -day turkey poults. These treatments also reduced the $S$. Heidelberg invasion of the liver and spleen [164]. In addition, these combinations were also found to be effective in 7-week-old and 12-week-old-turkeys (unpublished data).

We also found plant-derived compounds such as trans-cinnamaldehyde and pimenta essential oil were effective against multidrug-resistant $S$. Heidelberg isolated from ground turkey. Supplementation of trans-cinnamaldehyde through drinking water resulted in $4.5 \log _{10} \mathrm{CFU} / \mathrm{g}$ reduction in cecal colonization and reduced invasion of $S$. Heidelberg to the liver and spleen of 14-day old turkey poults [165]. Pimenta essential oil was effective against $S$. Heidelberg attached to the turkey skin. Our studies revealed that pimenta essential oil was effective against the multidrug-resistant $S$. Heidelberg attached to the turkey skin and resulted in $>2 \log _{10} \mathrm{CFU} / \mathrm{inch}^{2}$ reduction at simulated chilling or scalding conditions during processing [166]. More studies are ongoing in the laboratory exploring the potential of antibiotic alternatives against multidrug-resistant enteropathogens.

\section{Conclusions and Future Directions}

The issue of antibiotic resistance has resulted in far-reaching outcomes in human health and wellbeing due to the increased health care costs and productivity loss, and high proclivity towards acquiring other serious illnesses. A major issue with antibiotic resistance is that antibiotic-resistant clones of several major pathogens, including Salmonella, have been increasingly isolated from the food supply, including food animals, poultry, retail meat products, fresh produce, and seafood. All major resistance determinants, including those that confer resistance to $\beta$-lactams, extended spectrum $\beta$-lactams, fluoroquinolones, aminoglycosides, tetracyclines, and chloramphenicol, have been 
identified in various Salmonella serovars isolated from the food supply. It has become increasingly clear that antibiotic resistance will remain a significant hurdle to tackle in the near future. To address this issue, the FDA has issued the final rule to phase out antibiotics from production agriculture, curbing the use of clinically relevant antibiotics from production, and necessitating veterinary oversight on antibiotic use for therapy purposes in food animals and poultry. Responding to the situation, alternatives such as probiotics, prebiotics, phytobiotics, and others are being tested against drug-resistant pathogens, due to the broad spectrum of antimicrobial activity offered by these interventions. Ideally, the alternatives should not be toxic and should not result in residue build-up in the meat or eggs. It should be palatable to animals, stable in the gut, augment beneficial flora, and inactivate harmful pathogens. Additionally, these interventions will be tested for improved feed efficiency and growth without adversely affecting the environment [167]. Most importantly, they should not induce antimicrobial resistance in bacteria, including the beneficial gut microflora. Although studies targeting multiple serovars of Salmonella with these interventions are increasing, most of the studies are at their preliminary stages, warranting additional research to address significant gaps in the knowledge before recommending their use for improving preharvest and postharvest food safety. It will be a significant task to characterize, optimize, and scale-up these interventions to the level of potency and safety that antibiotics were providing in the past several decades.

Author Contributions: A.K.J. and K.V. contributed to the conceptualization; A.K.J. expanded the idea, designed the outline, and supervised the project; D.V.T.N. participated in the design, drafted the review, and made modifications and revisions jointly with A.K.J. to form the final manuscript; A.K.J. and K.V. critically reviewed and edited the manuscript.

Funding: The authors thank the USDA National Institute of Food and Agriculture Hatch Project support (\#MIN-16-120; Accession\#1016910) to AKJ at the University of Minnesota that covered the publication costs of this review.

Conflicts of Interest: The authors declare no conflicts of interest.

\section{References}

1. Bell, B.G.; Schellevis, F.; Stobberingh, E.; Goossens, H.; Pringle, M. A systematic review and meta-analysis of the effects of antibiotic consumption on antibiotic resistance. BMC Infect. Dis. 2014, 14, 1471-2334. [CrossRef] [PubMed]

2. Centers for Disease Control and Prevention (CDC). Antibiotic Resistance Threats in the United States. 2013. Available online: https://www.cdc.gov/drugresistance/pdf/ar-threats-2013-508.pdf (accessed on 24 October 2017).

3. Scallan, E.; Hoekstra, R.M.; Angulo, F.J.; Tauxe, R.V.; Widdowson, M.-A.; Roy, S.L.; Jones, J.L.; Griffin, P.M. Foodborne illness acquired in the United States-Major pathogens. Emerg. Infect. Dis. 2011, 17, 7-15. [CrossRef] [PubMed]

4. Centers for Disease Control and Prevention (CDC). Reports Selected Salmonella Outbreak Investigations. 2018. Available online: https:/ /www.cdc.gov/salmonella/outbreaks.html (accessed on 10 September 2018).

5. Centers for Disease Control and Prevention (CDC). Salmonella Urbana Infections Linked to Imported Maradol Papayas. 2017. Available online: https:/ / www.cdc.gov/salmonella/urbana-09-17/index.html (accessed on 10 September 2018).

6. Centers for Disease Control and Prevention (CDC). Multistate Outbreak of Salmonella Poona Infections Linked to Imported Cucumbers (Final Update). 2015. Available online: https:/ / www.cdc.gov/salmonella/ poona-09-15/index.html (accessed on 15 June 2018).

7. Centers for Disease Control and Prevention (CDC). Multistate Outbreak of Multidrug-Resistant Salmonella I 4,[5],12:i:- and Salmonella Infantis Infections Linked to Pork (Final Update). 2015. Available online: https: / www.cdc.gov/salmonella/pork-08-15/index.html (accessed on 10 September 2018).

8. Centers for Disease Control and Prevention (CDC). Salmonella Enteritidis Infections Linked to Raw, Frozen, Stuffed Chicken Entrees (Final Update). 2015. Available online: https:/ /www.cdc.gov/salmonella/frozenchicken-entrees-part2-07-15/index.html (accessed on 10 September 2018). 
9. Centers for Disease Control and Prevention (CDC). Salmonella Heidelberg Infections Linked to Tyson Brand Mechanically Separated Chicken at a Correctional Facility (Final Update). 2014. Available online: https:/ / www.cdc.gov/salmonella/heidelberg-01-14/index.html (accessed on 10 September 2018).

10. Centers for Disease Control and Prevention (CDC). Multistate Outbreak of Human Salmonella Heidelberg Infections Linked to Ground Turkey (Final Update). 2011. Available online: https://www.cdc.gov/ salmonella/2011/ground-turkey-11-10-2011.html (accessed on 10 September 2018).

11. Centers for Disease Control and Prevention (CDC). Multistate outbreak of Salmonella Typhimurium Infections Linked to Ground Beef (Final Update). 2012. Available online: https:/ /www.cdc.gov/salmonella/2011/ ground-beef-2-1-2012.html (accessed on 10 September 2018).

12. Centers for Disease Control and Prevention (CDC). Multistate Outbreak of Human Salmonella Hadar Infections Associated with Turkey Burgers (Final Update). 2011. Available online: https://www.cdc. gov/salmonella/2011/turkey-burger-4-4-2011.html (accessed on 10 September 2018).

13. Sneeringer, S.; MacDonald, J.; Key, N.; McBride, W.; Mathews, K. Economics of antibiotic use in U.S. swine and poultry production. Choices 2015, 30,1-11.

14. Mcewen, S.A.; Fedorka-Cray, P.J. Antimicrobial use and resistance in animals. Clin. Infect. Dis. 2002, 34, S93-S106. [CrossRef] [PubMed]

15. Mellon, M.; Benbrook, C.; Benbrook, K. Hogging It: Estimates of Antimicrobial Abuse in Livestock; Cambridge Union Concerned Scientists: Cambridge, MA, USA, 2001.

16. Landers, T.F.; Cohen, B.; Wittum, T.E.; Larson, E.L. A review of antibiotic use in food animals: Perspective, policy, and potential. Public Health Rep. 2012, 127, 4-22. [CrossRef] [PubMed]

17. Alali, W.Q.; Thakur, S.; Berghaus, R.D.; Martin, M.P.; Gebreyes, W.A. Prevalence and distribution of Salmonella in organic and conventional broiler poultry farms. Foodborne Pathog. Dis. 2010, 7, 1363-1371. [CrossRef] [PubMed]

18. Gebreyes, W.A.; Thakur, S.; Morgan Morrow, A.W.E. Comparison of prevalence, antimicrobial resistance, and occurrence of multidrug-resistant Salmonella in antimicrobial-free and conventional pig production. J. Food Prot. 2006, 69, 743-748. [CrossRef] [PubMed]

19. Thakur, S.; Tadesse, D.A.; Morrow, M.; Gebreyes, W.A. Occurrence of multidrug resistant Salmonella in antimicrobial-free (ABF) swine production systems. Vet. Microbiol. 2007, 125, 362-367. [CrossRef] [PubMed]

20. Manyi-Loh, C.; Mamphweli, S.; Meyer, E.; Okoh, A. Antibiotic use in agriculture and its consequential resistance in environmental sources: Potential public health implications. Molecules 2018, 23, 795. [CrossRef] [PubMed]

21. Wright, G.D. Antibiotic resistance in the environment: A link to the clinic? Curr. Opin. Microbiol. 2010, 13, 589-594. [CrossRef] [PubMed]

22. Mathur, S.; Singh, R. Antibiotic resistance in food lactic acid bacteria-A review. Int. J. Food Microbiol. 2005, 105, 281-295. [CrossRef] [PubMed]

23. Heyndrickx, M.; Vandekerchove, D.; Herman, L.; Rollier, I.; Grijspeerdt, K.; De Zutter, L. Routes for Salmonella contamination of poultry meat: Epidemiological study from hatchery to slaughterhouse. Epidemiol. Infect. 2002, 129, 253-265. [CrossRef] [PubMed]

24. Dorr, P.M.; Tadesse, D.A.; Zewde, B.M.; Fry, P.; Thakur, S.; Gebreyes, W.A. Longitudinal study of Salmonella dispersion and the role of environmental contamination in commercial swine production systems. Appl. Environ. Microbiol. 2009, 75, 1478-1486. [CrossRef] [PubMed]

25. Done, H.Y.; Venkatesan, A.K.; Halden, R.U. Does the recent growth of aquaculture create antibiotic resistance threats different from those associated with land animal production in agriculture? AAPS J. 2015, 17, 513-524. [CrossRef] [PubMed]

26. Liu, S.; Kilonzo-Nthenge, A. Prevalence of multidrug-resistant bacteria from U.S.-grown and imported fresh produce retailed in chain supermarkets and ethnic stores of Davidson County, Tennessee. J. Food Prot. 2017, 80, 506-514. [CrossRef] [PubMed]

27. Brandl, M.T. Fitness of human enteric pathogens on plants and implications for food safety. Annu. Rev. Phytopathol. 2006, 44, 367-392. [CrossRef] [PubMed]

28. Food and Drug Administration (FDA). Veterinary Feed Directive (VFD); FDA: Silver Spring, MD, USA, 2018. Available online: https:/ /www.fda.gov/animalveterinary/developmentapprovalprocess/ucm071807.htm (accessed on 1 October 2018). 
29. Food and Drug Administration (FDA). Development \& Approval Process-FACT SHEET: Veterinary Feed Directive Final Rule and Next Steps; FDA: Silver Spring, MD, USA, 2015.

30. Braden, C.R. Salmonella enterica serotype Enteritidis and eggs: A national epidemic in the United States. Clin. Infect. Dis. 2006, 43, 512-517. [CrossRef] [PubMed]

31. National Antimicrobial Resistance Monitoring System (NARMS). Human Isolates Final Report, 1998-NARMS National Antimicrobial Resistance Monitoring System: Enteric Bacteria; CDC: Atlanta, GA, USA, 2003. Available online: https: / /www.cdc.gov/narms/annual/1998/1998AnnualReport.pdf (accessed on 1 October 2018).

32. Al-Zenki, S.; Al-Nasser, A.; Al-Safar, A.; Alomirah, H.; Al-Haddad, A.; Hendriksen, R.S.; Aarestrup, F.M. Prevalence and antibiotic resistance of Salmonella isolated from a poultry farm and processing plant environment in the state of Kuwait. Foodborne Pathog. Dis. 2007, 4, 367-373. [CrossRef] [PubMed]

33. Jørgensen, F.; Bailey, R.; Williams, S.; Henderson, P.; Wareing, D.R.A.; Bolton, F.J.; Frost, J.A.; Ward, L.; Humphrey, T.J. Prevalence and numbers of Salmonella and Campylobacter spp. on raw, whole chickens in relation to sampling methods. Int. J. Food Microbiol. 2002, 76, 151-164. [CrossRef]

34. Food and Drug Administration (FDA). 2014-2015 Retail Meat Interim Report. 2017. Available online: https:/ / www.fda.gov/downloads / AnimalVeterinary/SafetyHealth/AntimicrobialResistance/ NationalAntimicrobialResistanceMonitoringSystem/UCM498134.pdf (accessed on 15 June 2018).

35. Kelley, T.R.; Pancorbo, O.C.; Merka, W.C.; Barnhart, H.M. Antibiotic resistance of bacterial litter isolates. Poult. Sci. 1998, 77, 243-247. [CrossRef] [PubMed]

36. Chen, Z.; Jiang, X. Microbiological safety of chicken litter or chicken litter-based organic fertilizers: A review. Agriculture 2014, 4, 1-29. [CrossRef]

37. Liljebjelke, K.A.; Hofacre, C.L.; White, D.G.; Ayers, S.; Lee, M.D.; Maurer, J.J. Diversity of antimicrobial resistance phenotypes in Salmonella isolated from commercial poultry farms. Front. Vet. Sci. 2017, 4, 96. [CrossRef] [PubMed]

38. Medeiros, M.A.N.; de Oliveira, D.C.N.; Rodrigues, D.P.; de Freitas, D.R.C. Prevalence and antimicrobial resistance of Salmonella in chicken carcasses at retail in 15 Brazilian cities. Rev. Panam. Salud. Publica. 2011, 30, 555-560. [CrossRef] [PubMed]

39. Dutil, L.; Irwin, R.; Finley, R.; Ng, L.K.; Avery, B.; Boerlin, P.; Bourgault, A.M.; Cole, L.; Daignault, D.; Desruisseau, A.; et al. Ceftiofur resistance in Salmonella enterica serovar Heidelberg from chicken meat and humans, Canada. Emerg. Infect. Dis. 2010, 16, 48-54. [CrossRef] [PubMed]

40. Duffy, G.; Cloak, O.M.; O'sullivan, M.G.; Guillet, A.; Sheridan, J.J.; Blair, I.S.; Mcdowell, D.A. The incidence and antibiotic resistance profiles of Salmonella spp. on Irish retail meat products. Food Microbiol. 1999, 16, 623-631. [CrossRef]

41. White, D.G.; Zhao, S.; Sudler, R.; Ayers, S.; Friedman, S.; Chen, S.; McDermott, P.F.; McDermott, S.; Wagner, D.D.; Meng, J. The isolation of antibiotic-resistant Salmonella from retail ground meats. N. Engl. J. Med. 2001, 345, 1147-1154. [CrossRef] [PubMed]

42. M'ikanatha, N.M.; Sandt, C.H.; Localio, A.R.; Tewari, D.; Rankin, S.C.; Whichard, J.M.; Altekruse, S.F.; Lautenbach, E.; Folster, J.P.; Russo, A.; et al. Multidrug-resistant Salmonella isolates from retail chicken meat compared with human clinical isolates. Foodborne Pathog. Dis. 2010, 7, 929-934. [CrossRef] [PubMed]

43. Chen, S.; Zhao, S.; White, D.G.; Schroeder, C.M.; Lu, R.; Yang, H.; McDermott, P.F.; Ayers, S.; Meng, J. Characterization of multiple-antimicrobial-resistant Salmonella serovars isolated from retail meats. Appl. Environ. Microbiol. 2004, 70, 1-7. [CrossRef] [PubMed]

44. Parveen, S.; Taabodi, M.; Schwarz, J.G.; Oscar, T.P.; Harter-Dennis, J.; White, D.G. Prevalence and antimicrobial resistance of Salmonella recovered from processed poultry. J. Food Prot. 2007, 70, 2466-2472. [CrossRef] [PubMed]

45. Sapkota, A.R.; Kinney, E.L.; George, A.; Hulet, R.M.; Cruz-Cano, R.; Schwab, K.J.; Zhang, G.; Joseph, S.W. Lower prevalence of antibiotic-resistant Salmonella on large-scale U.S. conventional poultry farms that transitioned to organic practices. Sci. Total Environ. 2014, 476-477, 387-392. [CrossRef] [PubMed]

46. Cui, S.; Ge, B.; Zheng, J.; Meng, J. Prevalence and antimicrobial resistance of Campylobacter spp. and Salmonella serovars in organic chickens from Maryland retail stores. Appl. Environ. Microbiol. 2005, 71, 4108-4111. [CrossRef] [PubMed]

47. Kunze, D.J.; Loneragan, G.H.; Platt, T.M.; Miller, M.F.; Besser, T.E.; Koohmaraie, M.; Stephens, T.; Brashears, M.M. Salmonella enterica burden in harvest-ready cattle populations from the southern high plains of the United States. Appl. Environ. Microbiol. 2008, 74, 345-351. [CrossRef] [PubMed] 
48. Schmidt, J.W.; Agga, G.E.; Bosilevac, J.M.; Brichta-Harhay, D.M.; Shackelford, S.D.; Wang, R.; Wheeler, T.L.; Arthur, T.M. Occurrence of antimicrobial-resistant Escherichia coli and Salmonella enterica in the beef cattle production and processing continuum. Appl. Environ. Microbiol. 2015, 81, 713-725. [CrossRef] [PubMed]

49. Gragg, S.E.; Loneragan, G.H.; Brashears, M.M.; Arthur, T.M.; Bosilevac, J.M.; Kalchayanand, N.; Wang, R.; Schmidt, J.W.; Brooks, J.C.; Shackelford, S.D.; et al. Cross-sectional study examining Salmonella enterica carriage in subiliac lymph nodes of cull and feedlot cattle at harvest. Foodborne Pathog. Dis. 2013, 10, 368-374. [CrossRef] [PubMed]

50. Zhao, T.; Doyle, M.P.; Fedorka-Cray, P.J.; Zhao, P.; Ladely, S. Occurrence of Salmonella enterica serotype Typhimurium DT104A in retail ground beef. J. Food Prot. 2002, 65, 403-407. [CrossRef] [PubMed]

51. Cobbold, R.N.; Rice, D.H.; Davis, M.A.; Besser, T.E.; Hancock, D.D. Long-term persistence of multi-drug-resistant Salmonella enterica serovar Newport in two dairy herds. J. Am. Vet. Med. Assoc. 2006, 228, 585-591. [CrossRef] [PubMed]

52. Rodriguez-Rivera, L.D.; Wright, E.M.; Siler, J.D.; Elton, M.; Cummings, K.J.; Warnick, L.D.; Wiedmann, M.; Wiedmann, M. Subtype analysis of Salmonella isolated from subclinically infected dairy cattle and dairy farm environments reveals the presence of both human-and bovine-associated subtypes. Vet. Microbiol. 2014, 4, 307-316. [CrossRef] [PubMed]

53. Cummings, K.J.; Warnick, L.D.; Alexander, K.A.; Cripps, C.J.; Gröhn, Y.T.; Mcdonough, P.L.; Nydam, D.V.; Reed, K.E. The incidence of salmonellosis among dairy herds in the northeastern United States. J. Dairy Sci. 2009, 92, 3766-3774. [CrossRef] [PubMed]

54. Fey, P.D.; Safranek, T.J.; Rupp, M.E.; Dunne, E.F.; Ribot, E.; Iwen, P.C.; Bradford, P.A.; Angulo, F.J.; Hinrichs, S.H. Ceftriaxone-resistant Salmonella infection acquired by a child from cattle. N. Engl. J. Med. 2000, 342, 1242-1249. [CrossRef] [PubMed]

55. Cromwell, G.L. Why and how antibiotics are used in swine production. Anim. Biotechnol. 2002, 13, 7-27. [CrossRef] [PubMed]

56. Pornsukarom, S.; Thakur, S. Assessing the impact of manure application in commercial swine farms on the transmission of antimicrobial resistant Salmonella in the environment. PLoS ONE. 2016, 11, e0164621. [CrossRef] [PubMed]

57. Seuberlich, T.; Doherr, M.G.; Botteron, C.; Nicolier, A.; Heim, D.; Zurbriggen, A. Comparison of Salmonella serovar isolation and antimicrobial resistance patterns from porcine samples between 2003 and 2008. J. Vet. Diagn. Investig. 2009, 101, 97-101. [CrossRef] [PubMed]

58. Lynne, A.M.; Dorsey, L.L.; David, D.E.; Foley, S.L. Characterisation of antibiotic resistance in host-adapted Salmonella enterica. Int. J. Antimicrob. Agents 2009, 34, 169-172. [CrossRef] [PubMed]

59. Vugia, D.J.; Samuel, M.; Farley, M.M.; Marcus, R.; Shiferaw, B.; Shallow, S.; Smith, K.; Angulo, F.J. Invasive Salmonella infections in the United States, FoodNet, 1996-1999: Incidence, serotype distribution, and outcome. Clin. Infect. Dis. 2004, 38, S149-S156. [CrossRef] [PubMed]

60. Baggesen, D.L.; Aarestrup, F.M. Characterisation of recently emerged multiple antibiotic-resistant Salmonella enterica serovar Typhimurium DT104 and other multiresistant phage types from Danish pig herds. Vet. Rec. 1998, 143, 95-97. [CrossRef] [PubMed]

61. Perron, G.G.; Quessy, S.; Bell, G.; Carter, D.A. A reservoir of drug-resistant pathogenic bacteria in asymptomatic hosts. PLoS ONE 2008, 3, e3749. [CrossRef] [PubMed]

62. Gebreyes, W.A.; Thakur, S.; Davies, P.R.; Funk, J.A.; Altier, C. Trends in antimicrobial resistance, phage types and integrons among Salmonella serotypes from pigs, 1997-2000. J. Antimicrob. Chemother. 2004, 53, 997-1003. [CrossRef] [PubMed]

63. Gebreyes, W.A.; Thakur, S. Multidrug-resistant Salmonella enterica serovar Muenchen from pigs and humans and potential interserovar transfer of antimicrobial resistance. Antimicrob. Agents Chemother. 2005, 49, 503-511. [CrossRef] [PubMed]

64. Mollenkopf, D.F.; Kleinhenz, K.E.; Funk, J.A.; Gebreyes, W.A.; Wittum, T.E. Salmonella enterica and Escherichia coli harboring bla CMY in retail beef and pork products. Foodborne Pathog. Dis. 2011, 8, 333-336. [CrossRef] [PubMed]

65. Johnson, R. The U.S. Trade Situation for Fruit and Vegetable Products Renée Johnson Specialist in Agricultural Policy. 2014. Available online: http:/ / nationalaglawcenter.org/wp-content/uploads/assets/crs /RL34468. pdf (accessed on 15 June 2018). 
66. Denis, N.; Zhang, H.; Leroux, A.; Trudel, R.; Bietlot, H. Prevalence and trends of bacterial contamination in fresh fruits and vegetables sold at retail in Canada. Food Control. 2016, 67, 225-234. [CrossRef]

67. Duffy, E.A.; Lucia, L.M.; Kells, J.M.; Castillo, A.; Pillai, S.D.; Acuff, G.R. Concentrations of Escherichia coli and genetic diversity and antibiotic resistance profiling of Salmonella isolated from irrigation water, packing shed equipment, and fresh produce in Texas. J. Food Prot. 2005, 68, 70-79. [CrossRef] [PubMed]

68. Li, B.; Vellidis, G.; Liu, H.; Jay-Russell, M.; Zhao, S.; Hu, Z.; Wright, A.; Elkins, C.A. Diversity and antimicrobial resistance of Salmonella enterica isolates from surface water in southeastern United States. Appl. Environ. Microbiol. 2014, 80, 6355-6365. [CrossRef] [PubMed]

69. Jay-Russell, M.T.; Hake, A.F.; Bengson, Y.; Thiptara, A.; Nguyen, T. Prevalence and characterization of Escherichia coli and Salmonella strains isolated from stray dog and coyote feces in a major leafy greens production region at the United States-Mexico border. PLoS ONE 2014, 9, e113433. [CrossRef] [PubMed]

70. Gorski, L.; Jay-Russell, M.T.; Liang, A.S.; Walker, S.; Bengson, Y.; Govoni, J.; Mandrell, R.E. Diversity of pulsed-field gel electrophoresis pulsotypes, serovars, and antibiotic resistance among Salmonella isolates from wild amphibians and reptiles in the California central coast. Foodborne Pathog. Dis. 2013, 10, 540-548. [CrossRef] [PubMed]

71. Islam, M.; Morgan, J.; Doyle, M.P.; Phatak, S.C.; Millner, P.; Jiang, X. Persistence of Salmonella enterica serovar Typhimurium on lettuce and parsley and in soils on which they were grown in fields treated with contaminated manure composts or irrigation water. Foodborne Pathog. Dis. 2004, 1, 27-35. [CrossRef] [PubMed]

72. Feldhusen, F. The role of seafood in bacterial foodborne diseases. Microbes Infect. 2000, 2, 1651-1660. [CrossRef]

73. Khan, A.A.; Ponce, E.; Nawaz, M.S.; Cheng, C.-M.; Khan, J.A.; West, C.S. Identification and characterization of class 1 Integron resistance gene cassettes among Salmonella strains isolated from imported seafood. Appl. Environ. Microbiol. 2009, 75, 1192-1196. [CrossRef] [PubMed]

74. Brands, D.A.; Billington, S.J.; Levine, J.F.; Joens, L.A. Genotypes and antibiotic resistance of Salmonella Newport isolates from U.S. market oysters. Foodborne Pathog. Dis. 2005, 2, 111-114. [CrossRef] [PubMed]

75. Wang, F.; Jiang, L.; Yang, Q.; Han, F.; Chen, S.; Pu, S.; Vance, A.; Ge, B. Prevalence and antimicrobial susceptibility of major foodborne pathogens in imported seafood. J. Food Prot. 2011, 74, 1451-1461. [CrossRef] [PubMed]

76. Boinapally, K.; Jiang, X. Comparing antibiotic resistance in commensal and pathogenic bacteria isolated from wild-caught South Carolina shrimps vs. farm-raised imported shrimps. Can. J. Microbiol. 2007, 53, 919-924. [CrossRef] [PubMed]

77. Dur, G.M.; And, N.; Marshall, D.L. Ready-to-eat shrimp as an international vehicle of antibiotic-resistant bacteria. J. Food Prot. 2005, 68, 2395-2401.

78. Centers for Disease Control and Prevention (CDC). Multistate outbreak of Salmonella Paratyphi B variant L(+) tartrate(+) and Salmonella Weltevreden infections linked to frozen raw Tuna (Final Update). 2015. Available online: https: / /www.cdc.gov/salmonella/paratyphi-b-05-15/index.html (accessed on 15 June 2018).

79. Carattoli, A. Plasmid-mediated antimicrobial resistance in Salmonella enterica. Curr. Issues Mol. Biol. 2003, 5, 113-122. [PubMed]

80. Domingues, S.; da Silva, G.J.; Nielsen, K.M. Integrons: Vehicles and pathways for horizontal dissemination in bacteria. Mob. Genet. Elements. 2012, 2, 211-223. [CrossRef] [PubMed]

81. Velge, P.; Cloeckaert, A.; Barrow, P. Emergence of Salmonella epidemics: The problems related to Salmonella enterica serotype Enteritidis and multiple antibiotic resistance in other major serotypes. Vet. Res. 2005, 36, 267-288. [CrossRef] [PubMed]

82. Griggs, D.J.; Gensberg, K.; Piddock, L.J. Mutations in gyrA gene of quinolone-resistant Salmonella serotypes isolated from humans and animals. Antimicrob. Agents Chemother. 1996, 40, 1009-1013. [CrossRef] [PubMed]

83. Giraud, E.; Cloeckaert, A.; Kerboeuf, D.; Chaslus-Dancla, E. Evidence for active efflux as the primary mechanism of resistance to ciprofloxacin in Salmonella enterica serovar Typhimurium. Antimicrob. Agents Chemother. 2000, 44, 1223-1228. [CrossRef] [PubMed]

84. Wong, M.H.; Chan, E.W.; Liu, L.Z.; Chen, S. PMQR genes oqxAB and aac (6')Ib-cr accelerate the development of fluoroquinolone resistance in Salmonella Typhimurium. Front. Microbiol. 2014, 5, 521. [CrossRef] [PubMed] 
85. Baucheron, S.; Imberechts, H.; Chaslus-Dancla, E.; Cloeckaert, A. The AcrB multidrug transporter plays a major role in high-level fluoroquinolone resistance in Salmonella enterica serovar Typhimurium Phage Type DT204. Microb. Drug Resist. 2002, 8, 281-289. [CrossRef] [PubMed]

86. Baucheron, S.; Chaslus-Dancla, E.; Cloeckaert, A. Role of TolC and parC mutation in high-level fluoroquinolone resistance in Salmonella enterica serotype Typhimurium DT204. J. Antimicrob. Chemother. 2004, 53, 657-659. [CrossRef] [PubMed]

87. Hur, J.; Jawale, C.; Lee, J.H. Antimicrobial resistance of Salmonella isolated from food animals: A review. Food Res. Int. 2012, 45, 819-830. [CrossRef]

88. Blair, J.M.A.; Webber, M.A.; Baylay, A.J.; Ogbolu, D.O.; Piddock, L.J.V. Molecular mechanisms of antibiotic resistance. Nat. Rev. Microbiol. 2015, 13, 42-51. [CrossRef] [PubMed]

89. Shaikh, S.; Fatima, J.; Shakil, S.; Rizvi, S.M.D. Antibiotic resistance and extended spectrum beta-lactamases: Types, epidemiology and treatment. Saudi J. Biol. Sci. 2015, 22, 90-101. [CrossRef] [PubMed]

90. Bradford, P.A. Extended-spectrum beta-lactamases in the 21st century: Characterization, epidemiology, and detection of this important resistance threat. Clin. Microbiol. Rev. 2001, 14, 933-951. [CrossRef] [PubMed]

91. Wu, H.; Wang, Y.; Wu, Y.; Qiao, J.; Li, H.; Zheng, S.; Xia, X.; Cui, S.; Wang, X.; Xi, M.; et al. Emergence of $\beta$-lactamases and extended-spectrum $\beta$-lactamases (ESBLs) producing Salmonella in retail raw chicken in China. Foodborne Pathog. Dis. 2015, 12, 228-234. [CrossRef] [PubMed]

92. Gray, J.T.; Hungerford, L.L.; Fedorka-Cray, P.J.; Headrick, M.L. Extended-spectrum-cephalosporin resistance in Salmonella enterica isolates of animal origin. Antimicrob. Agents Chemother. 2004, 48, 3179-3181. [CrossRef] [PubMed]

93. Tzouvelekis, L.; Tzelepi, E.; Tassios, P.; Legakis, N. CTX-M-type $\beta$-lactamases: An emerging group of extended-spectrum enzymes. Int. J. Antimicrob. Agents 2000, 14, 137-142. [CrossRef]

94. Bush, K.; Jacoby, G.A.; Medeiros, A.A. A functional classification scheme for beta-lactamases and its correlation with molecular structure. Antimicrob. Agents Chemother. 1995, 39, 1211-1233. [CrossRef] [PubMed]

95. Seiffert, S.N.; Perreten, V.; Johannes, S.; Droz, S.; Bodmer, T.; Endimiani, A. OXA-48 carbapenemase-producing Salmonella enterica serovar Kentucky isolate of sequence type 198 in a patient transferred from Libya to Switzerland. Antimicrob. Agents Chemother. 2014, 58, 2446-2449. [CrossRef] [PubMed]

96. Miriagou, V.; Tassios, P.T.; Legakis, N.J.; Tzouvelekis, L.S. Expanded-spectrum cephalosporin resistance in non-typhoid Salmonella. Int. J. Antimicrob. Agents 2004, 23, 547-555. [CrossRef] [PubMed]

97. Hanson, N.D.; Moland, E.S.; Hossain, A.; Neville, S.A.; Gosbell, I.B.; Thomson, K.S. Unusual Salmonella enterica serotype Typhimurium isolate producing CMY-7, SHV-9 and OXA-30 $\beta$-lactamases. J. Antimicrob. Chemother. 2002, 49, 1011-1014. [CrossRef] [PubMed]

98. Alcaine, S.D.; Warnick, L.D.; Wiedmann, M. Antimicrobial resistance in nontyphoidal Salmonella. J. Food. Prot. 2007, 70, 780-790. [CrossRef] [PubMed]

99. Roberts, M.C.; Schwarz, S. Tetracycline and phenicol resistance genes and mechanisms: Importance for agriculture, the environment, and humans. J. Environ. Qual. 2016, 45, 576-592. [CrossRef] [PubMed]

100. McDermott, P.F.; Tyson, G.H.; Kabera, C.; Chen, Y.; Li, C.; Folster, P.; Ayers, S.L.; Lam, C.; Tate, H.P.; Zhao, S. The use of whole genome sequencing for detecting antimicrobial resistance in nontyphoidal Salmonella. Antimicrob. Agents Chemother. 2016. [CrossRef] [PubMed]

101. Schwarz, S.; Kehrenberg, C.; Doublet, B.; Cloeckaert, A. Molecular basis of bacterial resistance to chloramphenicol and florfenicol. FEMS Microbiol. Rev. 2004, 28, 519-542. [CrossRef] [PubMed]

102. Huovinen, P.; Sundström, L.; Sundström, S.; Gö, G.; Swedberg, G.; Sköld, O.; Sköld, S. Trimethoprim and sulfonamide resistance. Antimicrob. Agents Chemother. 1995, 39, 279-289. [CrossRef] [PubMed]

103. Griggs, J.P.; Jacob, J.P. Alternatives to Antibiotics for Organic Poultry Production. J. Appl. Poult. Res. 2005, 14, 750-756. [CrossRef]

104. Tellez, G.; Pixley, C.; Wolfenden, R.E.; Layton, S.L.; Hargis, B.M. Probiotics/direct fed microbials for Salmonella control in poultry. Food Res. Int. 2012, 45, 628-633. [CrossRef]

105. Fuller, R. History and development of probiotics. In Probiotics; Springer: Dordrecht, The Netherlands, 1992; pp. 1-8.

106. Surendran Nair, M.; Amalaradjou, M.A.R.; Venkitanarayanan, K. Antivirulence properties of probiotics in combating microbial pathogenesis. Adv. Appl. Microbiol. 2017, 98, 1-29. [PubMed] 
107. Chambers, J.R.; Gong, J. The intestinal microbiota and its modulation for Salmonella control in chickens. Food Res. Int. 2011, 44, 3149-3159. [CrossRef]

108. De Waard, R.; Garssen, J.; Bokken, G.C.A.M.; Vos, J.G. Antagonistic activity of Lactobacillus casei strain Shirota against gastrointestinal Listeria monocytogenes infection in rats. Int. J. Food Microbiol. 2002, 73, 93-100. [CrossRef]

109. Ohya, T.; Marubashi, T.; Ito, H. Significance of fecal volatile fatty acids in shedding of Escherichia coli O157 from calves: Experimental infection and preliminary use of a probiotic product. J. Vet. Med. Sci. 2000, 62, 1151-1155. [CrossRef] [PubMed]

110. Patterson, J.; Burkholder, K. Application of prebiotics and probiotics in poultry production. Poult. Sci. 2003, 82, 627-631. [CrossRef] [PubMed]

111. Wolfenden, A.D.; Pixley, C.M.; Higgins, J.P.; Higgins, S.E.; Vicente, J.L.; Torres-Rodriguez, A.; Hargis, B.M.; Tellez, G. Evaluation of spray application of a Lactobacillus-based probiotic on Salmonella Enteritidis colonization in broiler chickens. Int. J. Poult. Sci. 2007, 6, 493-496. [CrossRef]

112. Higgins, S.E.; Higgins, J.P.; Wolfenden, A.D.; Henderson, S.N.; Torres-Rodriguez, A.; Tellez, G.; Hargis, B. Evaluation of a Lactobacillus-based probiotic culture for the reduction of Salmonella Enteritidis in neonatal broiler chicks. Poult. Sci. 2008, 87, 27-31. [CrossRef] [PubMed]

113. Menconi, A.; Wolfenden, A.D.; Shivaramaiah, S.; Terraes, J.C.; Urbano, T.; Kuttel, J.; Kremer, C.; Hargis, B.M.; Tellez, G. Effect of lactic acid bacteria probiotic culture for the treatment of Salmonella enterica serovar Heidelberg in neonatal broiler chickens and turkey poults. Poult. Sci. 2011, 90, 561-565. [CrossRef] [PubMed]

114. Pascual, M.; Hugas, M.; Badiola, J.I.; Monfort, J.M.; Garriga, M. Lactobacillus salivarius CTC2197 prevents Salmonella Enteritidis colonization in chickens. Appl. Environ. Microbiol. 1999, 65, 4981-4986. [PubMed]

115. Thirabunyanon, M.; Thongwittaya, N. Protection activity of a novel probiotic strain of Bacillus subtilis against Salmonella Enteritidis infection. Res. Vet. Sci. 2012, 93, 74-81. [CrossRef] [PubMed]

116. Barba-Vidal, E.; Castillejos, L.; Roll, V.F.B.; Cifuentes-Orjuela, G.; Moreno Muñoz, J.A.; Martín-Orúe, S.M. The probiotic combination of Bifidobacterium longum subsp. Infantis cect 7210 and Bifidobacterium animalis subsp. lactis bpl6 reduces pathogen loads and improves gut health of weaned piglets orally challenged with Salmonella Typhimurium. Front. Microbiol. 2017, 8, 1570. [CrossRef] [PubMed]

117. Yang, G.-Y.; Yu, J.; Su, J.-H.; Jiao, L.-G.; Liu, X.; Zhu, Y.-H. Oral Administration of Lactobacillus rhamnosus GG ameliorates Salmonella Infantis-induced inflammation in a pig model via activation of the IL-22BP/IL-22/STAT3 pathway. Front. Cell. Infect. Microbiol. 2017, 7, 323. [CrossRef] [PubMed]

118. Yin, F.; Farzan, A.; Wang, Q. (Chuck); Yu, H.; Yin, Y.; Hou, Y.; Friendship, R.; Gong, J. Reduction of Salmonella enterica serovar Typhimurium DT104 infection in experimentally challenged weaned pigs fed a Lactobacillus -fermented feed. Foodborne Pathog. Dis. 2014, 11, 628-634. [CrossRef] [PubMed]

119. Prieto, M.; O’Sullivan, L.; Tan, S.; McLoughlin, P.; Hughes, H.; Gutierrez, M.; Lane, J.; Hickey, R.; Lawlor, P.; Gardiner, G. In vitro assessment of marine Bacillus for use as livestock probiotics. Mar. Drugs. 2014, 12, 2422-2445. [CrossRef] [PubMed]

120. Vipham, J.L.; Loneragan, G.H.; Guillen, L.M.; Brooks, J.C.; Johnson, B.J.; Pond, A.; Pond, N.; Brashears, M.M. Reduced burden of Salmonella enterica in bovine subiliac lymph nodes associated with administration of a direct-fed microbial. Zoonoses Public Health 2015, 62, 599-608. [CrossRef] [PubMed]

121. Stephens, T.P.; Loneragan, G.H.; Karunasena, E.; Brashears, M.M. Reduction of Escherichia coli O157 and Salmonella in feces and on hides of feedlot cattle using various doses of a direct-fed microbial. J. Food Prot. 2007, 70, 2386-2391. [CrossRef] [PubMed]

122. Frizzo, L.S.; Zbrun, M.V.; Soto, L.P.; Bertozzi, E.; Sequeira, G.J.; Marti, L.E.; Signorini, M.L.; Armesto, R.R.; Rosmini, M.R. Pathogen translocation and histopathological lesions in an experimental model of Salmonella Dublin infection in calves receiving lactic acid bacteria and lactose supplements. J. Vet. Sci. 2012, 13, 261-270. [CrossRef] [PubMed]

123. Patel, S.; Goyal, A. The current trends and future perspectives of prebiotics research: A review. Biotech 2012, 2, 115-125. [CrossRef]

124. Blaut, M. Relationship of prebiotics and food to intestinal microflora. Eur. J. Nutr. 2002, 41, 1-16. [CrossRef] [PubMed]

125. Pourabedin, M.; Chen, Q.; Yang, M.; Zhao, X. Mannan- and xylooligosaccharides modulate caecal microbiota and expression of inflammatory-related cytokines and reduce caecal Salmonella Enteritidis colonisation in young chickens. FEMS Microbiol. Ecol. 2017, 93, fiw226. [CrossRef] [PubMed] 
126. Fernandez, F.; Hinton, M.; Gils, B. Van Dietary mannan-oligosaccharides and their effect on chicken caecal microflora in relation to Salmonella Enteritidis colonization. Avian Pathol. 2002, 31, 49-58. [CrossRef] [PubMed]

127. Eeckhaut, V.; Van Immerseel, F.; Dewulf, J.; Pasmans, F.; Haesebrouck, F.; Ducatelle, R.; Courtin, C.M.; Delcour, J.A.; Broekaert, W.F. Arabinoxylooligosaccharides from wheat bran inhibit Salmonella colonization in broiler chickens. Poult. Sci. 2008, 87, 2329-2334. [CrossRef] [PubMed]

128. Bouwhuis, M.A.; McDonnell, M.J.; Sweeney, T.; Mukhopadhya, A.; O'Shea, C.J.; O'Doherty, J.V. Seaweed extracts and galacto-oligosaccharides improve intestinal health in pigs following Salmonella Typhimurium challenge. Animal 2017, 11, 1488-1496. [CrossRef] [PubMed]

129. Tanner, S.A.; Chassard, C.; Zihler Berner, A.; Lacroix, C. Synergistic effects of Bifidobacterium thermophilum RBL67 and selected prebiotics on inhibition of Salmonella colonization in the swine proximal colon PolyFermS model. Gut Pathog. 2014, 6, 44. [CrossRef] [PubMed]

130. Tran, T.H.T.; Everaert, N.; Bindelle, J. Review on the effects of potential prebiotics on controlling intestinal enteropathogens Salmonella and Escherichia coli in pig production. J. Anim. Physiol. Anim. Nutr. 2016, 102, 17-32. [CrossRef] [PubMed]

131. Burt, S. Essential oils: Their antibacterial properties and potential applications in foods-A review. Int. J. Food Microbiol. 2004, 94, 223-253. [CrossRef] [PubMed]

132. Kollanoor-Johny, A.; Darre, M.J.; Donoghue, A.M.; Donoghue, D.J.; Venkitanarayanan, K. Antibacterial effect of trans-cinnamaldehyde, eugenol, carvacrol, and thymol on Salmonella Enteritidis and Campylobacter jejuni in chicken cecal contents in vitro. J. Appl. Poult. Res. 2010, 19, 237-244. [CrossRef]

133. Kollanoor-Johny, A.; Mattson, T.; Baskaran, S.A.; Amalaradjou, M.A.R.; Babapoor, S.; March, B.; Valipe, S.; Darre, M.; Hoagland, T.; Schreiber, D.; et al. Reduction of Salmonella enterica serovar Enteritidis colonization in 20-day-old broiler chickens by the plant-derived compounds trans-cinnamaldehyde and eugenol. Appl. Environ. Microbiol. 2012, 78, 2981-2987. [CrossRef] [PubMed]

134. Kollanoor-Johny, A.; Upadhyay, A.; Baskaran, S.A.; Upadhyaya, I.; Mooyottu, S.; Mishra, N.; Darre, M.J.; Khan, M.I.; Donoghue, A.M.; Donoghue, D.J.; et al. Effect of therapeutic supplementation of the plant compounds trans-cinnamaldehyde and eugenol on Salmonella enterica serovar Enteritidis colonization in market-age broiler chickens. J. Appl. Poult. Res. 2012, 21, 816-822. [CrossRef]

135. Surendran Nair, M.; Lau, P.; Belskie, K.; Fancher, S.; Chen, C.-H.; Karumathil, D.P.; Yin, H.-B.; Liu, Y.; Ma, F.; Upadhyaya, I.; et al. Potentiating the heat inactivation of Escherichia coli O157:H7 in ground beef patties by natural antimicrobials. Front. Microbiol. 2016, 7, 15. [CrossRef] [PubMed]

136. Surendran-Nair, M.; Kollanoor-Johny, A.; Ananda-Baskaran, S.; Norris, C.; Lee, J.-Y.; Venkitanarayanan, K. Selenium reduces enterohemorrhagic Escherichia coli O157:H7 verotoxin production and globotriaosylceramide receptor expression on host cells. Future Microbiol. 2016, 11, 745-756. [CrossRef] [PubMed]

137. Nair, D.V.T.; Nannapaneni, R.; Kiess, A.; Mahmoud, B.; Sharma, C.S. Antimicrobial efficacy of lauric arginate against Campylobacter jejuni and spoilage organisms on chicken breast fillets. Poult. Sci. 2014, 93, 2636-2640. [CrossRef] [PubMed]

138. Surendran Nair, M.; Upadhyay, A.; Fancher, S.; Upadhyaya, I.; Dey, S.; Kollanoor-Johny, A.; Zhao, J.; Venkitanarayanan, K. Inhibition and inactivation of Escherichia coli O157:H7 biofilms by Selenium. J. Food Prot. 2018, 81, 926-933. [CrossRef] [PubMed]

139. Kollanoor-Johny, A.; Frye, J.G.; Donoghue, A.; Donoghue, D.J.; Porwollik, S.; McClelland, M.; Venkitanarayanan, K. Gene Expression Response of Salmonella enterica serotype Enteritidis Phage Type 8 to subinhibitory concentrations of the plant-derived compounds trans-cinnamaldehyde and eugenol. Front. Microbiol. 2017, 8, 1-10. [CrossRef] [PubMed]

140. Kollanoor-Johny, A.; Darre, M.J.; Hoagland, T.A.; Schreiber, D.T.; Donoghue, A.M.; Donoghue, D.J.; Venkitanarayanan, K. Antibacterial Effect of trans-cinnamaldehyde on Salmonella Enteritidis and Campylobacter jejuni in chicken drinking water. J. Appl. Poult. Res. 2008, 17, 490-497. [CrossRef]

141. Nair, D.V.T.; Kiess, A.; Nannapaneni, R.; Schilling, W.; Sharma, C.S. The combined efficacy of carvacrol and modified atmosphere packaging on the survival of Salmonella, Campylobacter jejuni and lactic acid bacteria on turkey breast cutlets. Food Microbiol. 2015, 49, 134-141. [CrossRef] [PubMed]

142. Nair, D.V.T.; Nannapaneni, R.; Kiess, A.; Schilling, W.; Sharma, C.S. Reduction of Salmonella on Turkey breast cutlets by plant-derived compounds. Foodborne Pathog. Dis. 2014, 11, 981-987. [CrossRef] [PubMed] 
143. Baskaran, S.A.; Kollanoor-Johny, A.; Surendran Nair, M.; Venkitanarayanan, K. Efficacy of plant-derived antimicrobials in controlling Enterohemorrhagic Escherichia coli virulence in vitro. J. Food Prot. 2016, 79, 1965-1970. [CrossRef] [PubMed]

144. Nair, D.V.T. Efficacy of GRAS Antimicrobial Compounds and Modified Atmosphere Packaging in Reducing Salmonella, Campylobacter and Spoilage Organisms on Poultry Meat; Mississippi State University: Starkville, MS, USA, 2014.

145. Venkitanarayanan, K.; Kollanoor-Johny, A.; Darre, M.J.; Donoghue, A.M.; Donoghue, D.J. Use of plant-derived antimicrobials for improving the safety of poultry products. Poult. Sci. 2013, 92, 493-501. [CrossRef] [PubMed]

146. Surendran-Nair, M.; Upadhyaya, I.; Amalaradjou, M.A.R.; Venkitanarayanan, K. Antimicrobial food additives and disinfectants. In Foodborne Pathogens and Antibiotic Resistance; John Wiley \& Sons, Inc.: Hoboken, NJ, USA, 2017; pp. 275-301. ISBN 9781119139188.

147. Kollanoor-Johny, A.; Hoagland, T.; Venkitanarayanan, K. Effect of subinhibitory concentrations of plant-derived molecules in increasing the sensitivity of multidrug-resistant Salmonella enterica serovar Typhimurium DT104 to antibiotics. Foodborne Pathog. Dis. 2010, 7, 1165-1170. [CrossRef] [PubMed]

148. Inamuco, J.; Veenendaal, A.K.J.; Burt, S.A.; Post, J.A.; Tjeerdsma-Van Bokhoven, J.L.M.; Haagsman, H.P.; Veldhuizen, E.J.A. Sub-lethal levels of carvacrol reduce Salmonella Typhimurium motility and invasion of porcine epithelial cells. Vet. Microbiol. 2012, 157, 200-207. [CrossRef] [PubMed]

149. Mattson, T.E.; Kollanoor-Johny, A.; Amalaradjou, M.A.R.; More, K.; Schreiber, D.T.; Patel, J.; Venkitanarayanan, K. Inactivation of Salmonella spp. on tomatoes by plant molecules. Int. J. Food Microbiol. 2011, 144, 464-468. [CrossRef] [PubMed]

150. Chen, C.H.; Ravishankar, S.; Marchello, J.; Friedman, M. Antimicrobial activity of plant compounds against Salmonella Typhimurium DT104 in ground pork and the influence of heat and storage on the antimicrobial activity. J. Food Prot. 2013, 76, 1264-1269. [CrossRef] [PubMed]

151. Skandamis, P.; Tsigarida, E.; Nychas, G.-J.E. The effect of oregano essential oil on survival/death of Salmonella Typhimurium in meat stored at $5{ }^{\circ} \mathrm{C}$ under aerobic, VP/MAP conditions. Food Microbiol. 2002, 19, 97-103. [CrossRef]

152. Solomakos, N.; Govaris, A.; Koidis, P.; Botsoglou, N. The antimicrobial effect of thyme essential oil, nisin, and their combination against Listeria monocytogenes in minced beef during refrigerated storage. Food Microbiol. 2008, 25, 120-127. [CrossRef] [PubMed]

153. Van Immerseel, F.; Russell, J.B.; Flythe, M.D.; Gantois, I.; Timbermont, L.; Pasmans, F.; Haesebrouck, F.; Ducatelle, R. The use of organic acids to combat Salmonella in poultry: A mechanistic explanation of the efficacy. Avian Pathol. 2007, 35, 182-188. [CrossRef] [PubMed]

154. Messens, W.; Goris, J.; Dierick, N.; Herman, L.; Heyndrickx, M. Inhibition of Salmonella Typhimurium by medium chain fatty acids in an in vitro simulation of the porcine cecum. Vet. Microbiol. 2010, 141, 73-80. [CrossRef] [PubMed]

155. Boyen, F.; Haesebrouck, F.; Vanparys, A.; Volf, J.; Mahu, M.; Van Immerseel, F.; Rychlik, I.; Dewulf, J.; Ducatelle, R.; Pasmans, F. Coated fatty acids alter virulence properties of Salmonella Typhimurium and decrease intestinal colonization of pigs. Vet. Microbiol. 2008, 132, 319-327. [CrossRef] [PubMed]

156. Rasschaert, G.; Michiels, J.; Tagliabue, M.; Missotten, J.; De Smet, S.; Heyndrickx, A.M. Effect of organic acids on Salmonella shedding and colonization in Pigs on a farm with high Salmonella prevalence. J. Food Prot. 2016, 79, 51-58. [CrossRef] [PubMed]

157. Evans, N.P.; Collins, D.A.; Pierson, F.W.; Mahsoub, H.M.; Sriranganathan, N.; Persia, M.E.; Karnezos, T.P.; Sims, M.D.; Dalloul, R.A. Investigation of medium chain fatty acid feed supplementation for reducing Salmonella Typhimurium colonization in turkey poults. Foodborne Pathog. Dis. 2017, 14, 531-536. [CrossRef] [PubMed]

158. Kollanoor-Johny, A.; Ananda Baskaran, S.; Susan Charles, A.; Amalaradjou, M.A.R.; Darre, M.J.; Khan, M.I.; Hoagland, T.A.; Schreiber, D.T.; Donoghue, A.M.; Donoghue, D.J.; et al. Prophylactic Supplementation of caprylic acid in feed reduces Salmonella Enteritidis colonization in commercial broiler chicks. J. Food Prot. 2009, 72, 722-727. [CrossRef]

159. Kollanoor-Johny, A.; Mattson, T.; Baskaran, S.A.; Amalaradjou, M.A.R.; Hoagland, T.A.; Darre, M.J.; Khan, M.I.; Schreiber, D.T.; Donoghue, A.M.; Donoghue, D.J.; et al. Caprylic acid reduces Salmonella Enteritidis populations in various segments of digestive tract and internal organs of 3- and 6-week-old broiler chickens, therapeutically. Poult. Sci. 2012, 91, 1686-1694. [CrossRef] [PubMed] 
160. Van Immerseel, F.; De Buck, J.; Boyen, F.; Bohez, L.; Pasmans, F.; Volf, J.; Sevcik, M.; Rychlik, I.; Haesebrouck, F.; Ducatelle, R. Medium-chain fatty acids decrease colonization and invasion through hilA suppression shortly after infection of chickens with Salmonella enterica serovar Enteritidis. Appl. Environ. Microbiol. 2004, 70, 3582-3587. [CrossRef] [PubMed]

161. Folster, J.P.; Pecic, G.; Rickert, R.; Taylor, J.; Zhao, S.; Fedorka-Cray, P.J.; Whichard, J.; McDermott, P.; McDermott, P.F.; Haro, J.; et al. Characterization of multidrug-resistant Salmonella enterica serovar Heidelberg from a ground turkey-associated outbreak in the United States in 2011. Antimicrob. Agents Chemother. 2012, 56, 3465-3466. [CrossRef] [PubMed]

162. Nair, D.V.T.; Kollanoor-Johny, A. Effect of Propionibacterium freudenreichii on Salmonella multiplication, motility, and association with avian epithelial cells. Poult. Sci. 2017, 96, 1376-1386.

163. Nair, D.V.T.; Kollanoor-Johny, A. Characterizing the antimicrobial function of a dairy-originated probiotic, Propionibacterium freudenreichii, against multidrug-resistant Salmonella enterica serovar Heidelberg in turkey poults. Front. Microbiol. 2018. [CrossRef] [PubMed]

164. Nair, D.V.T.; Thomas, J.V.; Dewi, G.; Johnson, T.; Noll, S.; Cardona, C.; Kollanoor-Johny, A. Effects of Multiple Alternatives-To-Antibiotic Interventions on Multidrug-Resistant Salmonella Heidelberg in Turkey Poults. In Proceedings of the 2017 PSA Annual Meeting, Orlando, FL, USA, 17-20 July 2017; Volume 96, p. 24.

165. Nair, D.V.T.; Thomas, J.V.; Kollanoor-Johny, A. Effect of Supplementation of Trans-Cinnamaldehyde with or without Oxytetracycline on Multidrug-Resistant Salmonella Heidelberg in Turkey Poults. In Proceedings of the 2017 PSA Annual Meeting, Orlando, FL, USA, 17-20 July 2017; Volume 96, p. 93.

166. Nair, D.V.T.; Kollanoor-Johny, A. Food grade pimenta leaf essential oil reduces the attachment of Salmonella enterica Heidelberg (2011 ground turkey outbreak isolate) on to turkey Skin. Front. Microbiol. 2017, 8. [CrossRef] [PubMed]

167. Cheng, G.; Hao, H.; Xie, S.; Wang, X.; Dai, M.; Huang, L.; Yuan, Z. Antibiotic alternatives: The substitution of antibiotics in animal husbandry? Front. Microbiol. 2014. [CrossRef] [PubMed]

(C) 2018 by the authors. Licensee MDPI, Basel, Switzerland. This article is an open access article distributed under the terms and conditions of the Creative Commons Attribution (CC BY) license (http:/ / creativecommons.org/licenses/by/4.0/). 